Article

\title{
The Modelling of Surface Roughness after the Ball Burnishing Process with a High-Stiffness Tool by Using Regression Analysis, Artificial Neural Networks, and Support Vector Regression
}

\author{
Zeljko Kanovic $^{1} \mathbb{D}$, Djordje Vukelic ${ }^{1, * \mathbb{D}}$, Katica Simunovic ${ }^{2} \mathbb{D}$, Miljana Prica ${ }^{1}$, Tomislav Saric ${ }^{2}$, Branko Tadic ${ }^{3} \mathbb{D}$ \\ and Goran Simunovic ${ }^{2}$ (D) \\ 1 Faculty of Technical Sciences, University of Novi Sad, Trg Dositeja Obradovica 6, 21000 Novi Sad, Serbia; \\ kanovic@uns.ac.rs (Z.K.); miljana@uns.ac.rs (M.P.) \\ 2 Mechanical Engineering Faculty in Slavonski Brod, University of Slavonski Brod, Trg Ivane Brlic Mazuranic 2, \\ 35000 Slavonski Brod, Croatia; ksimunovic@unisb.hr (K.S.); tsaric@unisb.hr (T.S.); gsimunovic@unisb.hr (G.S.) \\ 3 Faculty of Engineering, University of Kragujevac, Sestre Janjic 6, 34000 Kragujevac, Serbia; btadic@kg.ac.rs \\ * Correspondence: vukelic@uns.ac.rs; Tel.: +381-21-485-2326
}

Citation: Kanovic, Z.; Vukelic, D.; Simunovic, K.; Prica, M.; Saric, T.;

Tadic, B.; Simunovic, G. The

Modelling of Surface Roughness after the Ball Burnishing Process with a High-Stiffness Tool by Using Regression Analysis, Artificial Neural Networks, and Support Vector Regression. Metals 2022, 12, 320 https://doi.org/10.3390/ met12020320

Academic Editor: Badis HADDAG

Received: 7 January 2022

Accepted: 9 February 2022

Published: 11 February 2022

Publisher's Note: MDPI stays neutral with regard to jurisdictional claims in published maps and institutional affiliations.

Copyright: (c) 2022 by the authors Licensee MDPI, Basel, Switzerland. This article is an open access article distributed under the terms and conditions of the Creative Commons Attribution (CC BY) license (https:// creativecommons.org/licenses/by/ $4.0 /)$.

\begin{abstract}
Surface roughness is an important indicator of the quality of the machined surface. One of the methods that can be applied to improve surface roughness is ball burnishing. Ball burnishing is a finishing process in which a ball is rolled over the workpiece surface. Defining adequate input variables of the ball burnishing process to ensure obtaining the required surface roughness is a typical problem in scientific research. This paper presents the results of experiments to investigate ball burnishing of AISI 4130 alloy steel with a high-stiffness tool and a ceramic ball. The experiments were conducted following a randomized full factorial design for different levels of input variables. The input variables included the initial arithmetic mean roughness (the initial surface roughness), the depth of ball penetration, the burnishing feed, and the burnishing ball diameter, while the output variable was the arithmetic mean roughness after ball burnishing (the final surface roughness). The surface roughness modeling was performed based on the experimental results, using regression analysis (RA), artificial neural network (ANN), and support vector regression (SVR). The regression model displayed large prediction errors at low surface roughness values (below $1 \mu \mathrm{m}$ ), but it proved to be reliable for higher roughness values. The ANN and SVR models have excellently predicted roughness across a range of input variables. Mean percentage error (MPE) during the experimental training research was $29.727 \%, 0.995 \%$, and $1.592 \%$, and MPE in the confirmation experiments was $34.534 \%, 1.559 \%$, and $2.164 \%$, for RA, ANN, and SVR, respectively. Based on the obtained MPEs, it can be concluded that the application of ANN and SVR was adequate for modeling the ball burnishing process and prediction of the roughness of the treated surface in terms of the possibility of practical application in real industrial conditions.
\end{abstract}

Keywords: ball burnishing; surface roughness; artificial neural networks; support vector regression; regression analysis

\section{Introduction}

Ball burnishing is a process in which the ball rolls on the surface and causes elastic, elastoplastic, and plastic deformations of the surface layer of the workpiece [1]. As a result, the workpiece changes shape, dimensions, roughness, hardness, stresses, etc. This process can provide excellent geometric specifications and high dimensional accuracy [2]. Prismatic and cylindrical workpieces are mainly processed, but complex-shaped surfaces can also be treated [3]. Ball burnishing can significantly increase wear resistance, fatigue resistance, corrosion resistance, etc. [4]. This process can manage various materials such 
as steel, copper, aluminum, brass, polymers, titanium, nickel-chromium-molybdenum, wood, etc. [5].

Ball burnishing tools use various functional mechanisms to generate burnishing force. Burnishing force is most often generated with the spring [6-15], pressurized fluid [16,17], and high stiffness tools [18-20]. There are also hybrid ball burnishing tools, such as vibrationassisted ball burnishing tools [21-32], magnetic-assisted ball burnishing tools [33,34], etc. Burnishing force is usually generated by a single ball, although ball burnishing tools with multiple balls also exist. Burnishing balls are mostly made of tungsten carbide, chromeplated steel, high-speed steel, high-hardened steel, silicon nitride and titanium, stainless steel, carbon steel, ceramic, and synthetic diamond.

Previously, the ball burnishing process was studied in numerous ways, most often by the use of experiments. The literature cites a variety of experimental research that applied different techniques to study the relationship between input and output variables in ball burnishing. The investigations are mainly based on the development of new burnishing tool concepts, as well as analysis of the effect of input process variables (burnishing load, feed, number of passes, lubricant, etc.) on output process variables (residual stresses, surface roughness, hardness, etc.). The cost and time are merely some of the disadvantages of the conducted investigations. Furthermore, the obtained results can only be applied in conditions equal to those of the conducted experiments. The consequence of such investigations is the emergence of research on the prediction and modeling of the ball burnishing process.

Another research direction is the research of the ball burnishing process based on finite element analysis (FEA) [35-42]. Three-dimensional finite element models were developed to predict the deformation mechanics, plastic flow, hardness, and residual stress [41]. The disadvantage of these studies is time, especially if many FEA iterations with different input variables are to be conducted. This significantly prolongs the testing time, and thus the related costs. Furthermore, a considerable problem with FEA is the accurate determination of the coefficient of friction. The coefficient of friction can be variable not only between the ball and the surface to be treated but also between the ball and the supporting elements in the ball burnishing tool. This coefficient is an important input for accurate analysis in FEA and has a dominant impact on the results [42].

In earlier studies of the ball burnishing process, the Taguchi method [43-50] and response surface methodology (RSM) [51-56] were widely used. The Taguchi method reduces the number of experiments required for analysis but considers only the main effects on the process and does not allow consideration of the interaction between the input variables. RSM approach provides obtaining empirical, i.e., regression models, which quantify the effect of input variables on the output variables of the ball burnishing process. RSM is used to generate a polynomial model that includes ball burnishing process variables, as well as to diagnose their statistical significance. These traditional methods, i.e., the Taguchi method and RSM, are not characterized by great adaptability, especially if the experimentally obtained dependencies between the input and output variables of the ball burnishing are complex.

As computer technology developed, soft computing methods have also begun to be used to model ball burnishing processes. Soft computing differs from conventional computing in that it tolerates inaccuracy, uncertainty, and approximation. Soft computing techniques have attracted the attention of researchers because of their potential to study multidimensional, nonlinear, and complex problems. For example, Cagan et al. [49] investigated the effect of burnishing parameters such as the number of passes, burnishing force, burnishing speed, and feed rate on the surface roughness and hardness using different artificial neural network models. Basak and Goktas [57] used a fuzzy logic (FL) model to achieve the best parameters (number of revolutions, feed, number of passes, and pressure force), which affect surface roughness after the burnishing process. Al-Saeedi et al. [58] predicted surface roughness values by FL for dry and fluid burnishing in relation to burnishing speed, depth, and feed. Ibrahim et al. [59] studied the effect of burnishing parameters (feed, 
speed, force, and the number of balls) on surface roundness via fuzzy logic. Esme et al. [60] used grey-based FL for the optimization of the ball burnishing process. The burnishing force, the number of passes, feed, and burnishing speed were selected as input parameters. Surface roughness and hardness were selected as output parameters. Esme et al. [61] developed a surface roughness prediction model using an artificial neural network (ANN). The ANN model of surface roughness was developed considering the conditions as burnishing force, the number of tool passes, feed, and burnishing speed. Esme et al. [62] predicted surface roughness in the ball burnishing process using regression and ANN techniques. Surface roughness was taken as the output variable, and the burnishing force, the number of passes, feed rate, and burnishing speed were taken as input parameters. Basak et al. [63] and Basak and Sonmez [64] examined the effects of burnishing force, feed rate, and the number of passes on surface hardness and surface roughness. A new ANN model with different neuron structures and algorithms was developed. Magalhaes et al. [65] obtained residual surface stress and hardness values using an ANN. The ANN was employed to determine the recommended burnishing pressure values and number of passes. Stalin John and Vinayagam [66] developed a fuzzy neural network (FNN) to examine the effects of force, feed, ball diameter, and the number of passes on the surface roughness. Singh and Bilga [67] generated an FNN model using different burnishing parameters (number of revolution, feed, number of tool passes, and pressure force) to achieve the required surface roughness and hardness. In previous research in the field of soft computing, FL [57-60], ANN [49,61-65], and FNN [66,67] were used to model the ball burnishing process. There are a number of modeling methods. It is necessary to analyze them, make a comparison, and choose the appropriate method for the given processing conditions.

The study of ball burnishing processes based on experimental data in combination with modeling methods is the most promising for future research. This can reduce costs, minimize the subjective influence of the operator, and improve the performance of the ball burnishing process in the context of obtaining the necessary output variables. This enables a greater universality of application, greater objectivity, and lower costs. The underlying problem is the correct and accurate modeling of the ball burnishing process with small, i.e., acceptable errors that occur between the obtained (experimental) results and their predicted values. The modeling methods solve the problem in different ways, but the essence is identical, to simulate the actual ball burnishing process as realistically as possible. Nevertheless, unambiguous and universal criteria for the application of these methods cannot be defined. In recent years, researchers have studied the possibility of modeling the ball burnishing process. However, there are still some issues with the choice of the modeling method in terms of obtaining the most accurate prediction results. Therefore, it is necessary to model the process with different methods and compare the applied methodologies. Modeling of the ball burnishing process of AISI 4130 alloy steel with a high-stiffness tool and a ceramic ball was not previously performed. The experiments need to be conducted in different environments to obtain the practical data required by the industry.

Unlike previous research, this study aims to evaluate the surface roughness after the ball burnishing process with a high-stiffness tool based on a constant penetration depth of the ceramic ball. The influence of all possible combinations of input variables on the surface roughness of the ball burnishing process was evaluated. Additionally, the surface roughness modeling was performed after the ball burnishing process with regression analysis and ANN. In addition to these two techniques, modeling was performed by the support vector regression (SVR) method, which, to the best of the authors' knowledge, has not been used for this purpose so far. By using three methods, the surface roughness was modeled, and its prediction was performed in a wide range of input variables, even for those processing parameters for which no experimental research was conducted. These three methods were compared based on the accuracy of the prediction of the output variable of the ball burnishing process. The comparison was made based on the obtained 
deviations, i.e., percentage errors between the current (experimental) and predicted values. The validation of the developed models was conducted on many confirmation experiments.

The remainder of the paper is organized as follows. Section 2 describes the framework of the research work. In this section, the methods and materials used in the research were also described. Section 3 presents detailed results of conducted experimental research, as well as results of surface roughness modeling using regression analysis, artificial neural network, and support vector regression. In order to objectively evaluate the efficiency of all three developed models, confirmation experiments were also presented in Section 3. Section 4 provides a discussion of the results and demonstrates the analysis of the results. Section 5 includes a summary in the form of main conclusions, limitations, and future research directions.

\section{Materials and Methods}

The ball burnishing process was conducted on a milling machine (HAAS-Toolroom Mill TM-1HE, Haas, Oxnard, CA, USA) (Figure 1) in one pass at $1800 \mathrm{~mm} / \mathrm{min}$ burnishing speed. During the ball burnishing process, the rotation of the main spindle was blocked. The ball burnishing process was performed only with translational movements of the workpiece that was located and clamped in a vise. By considering the increasingly stringent environmental requirements, ball burnishing was conducted in a dry environment.

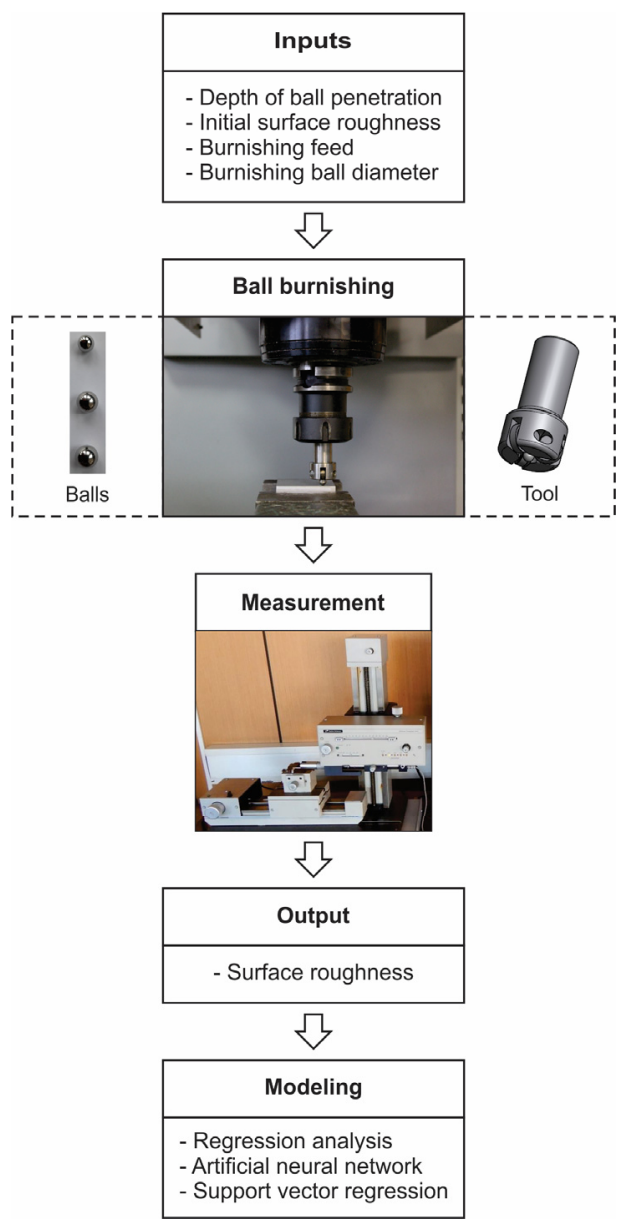

Figure 1. Graphical framework of the research work.

Four input variables were varied: the initial surface roughness, the depth of ball penetration, burnishing feed, and ball diameter. The output variable was the surface roughness after the ball burnishing process (the final surface roughness). 
The ball burnishing process was performed with a high-stiffness tool [18-20], which ensures ball rolling without sliding. The rolling of the ball was ensured by the construction of the high-stiffness tool. The ball and three roller bearings are housed in a common support. The three-roller bearings arranged at an angle of $120^{\circ}$ in relation to the direction of penetration of the ball into the material of the workpiece ensure that the ball rolls. The high-stiffness tool operates on the principle of the constant depth of ball penetration. The depth of penetration is given to the ball burnishing tool. The burnishing force necessary to perform the ball burnishing process is generated indirectly by setting the value of the depth of ball penetration into the workpiece. Ball burnishing with a high-stiffness tool, which is based on setting the depth of ball penetration, does not require additional equipment to achieve and monitor the required burnishing force. During ball burnishing, the surface layer of the workpiece is deformed. The peaks begin to deform and fill the valleys. This reduces the height parameters of surface roughness.

The research was conducted on prismatic workpieces made of steel AISI 4130. The chemical composition of workpieces is shown in Table 1, and the mechanical, physical, and thermal properties are presented in Table 2. This alloy 4130 steel is widely used, and some typical applications include commercial aircraft, aircraft engine mounts, military aircraft, automotive, machine tools, hydraulic tools, auto racing, aerospace, oil and gas industries, agricultural, defense industries, etc.

Table 1. Workpieces chemical composition.

\begin{tabular}{cc}
\hline Element & Content (\%) \\
\hline Iron & $97.03-98.22$ \\
Chromium & $0.80-1.10$ \\
Manganese & $0.40-0.60$ \\
Carbon & $0.28-0.33$ \\
Silicon & $0.15-0.30$ \\
Molybdenum & $0.15-0.25$ \\
Sulphur & 0.04 \\
Phosphorous & 0.035 \\
\hline
\end{tabular}

Table 2. Workpieces' mechanical, physical, and thermal properties.

\begin{tabular}{cc}
\hline Properties & Value \\
\hline Density & $7.85 \mathrm{~g} / \mathrm{cm}^{3}$ \\
Tensile strength & $560 \mathrm{MPa}$ \\
Yield strength & $460 \mathrm{MPa}$ \\
Modulus of elasticity & $200 \mathrm{GPa}$ \\
Poisson's ratio & 0.29 \\
Hardness & $37 \mathrm{HRC}$ \\
Thermal conductivity & $42.7 \mathrm{~W} / \mathrm{mK}$ \\
\hline
\end{tabular}

The experiments were conducted with ceramic balls made from silicon nitride $\left(\mathrm{Si}_{3} \mathrm{~N}_{4}\right)$ with the following chemical composition: silicon nitride $97 \%$, iron $0.5 \%$, carbon $0.3 \%$, silicon $0.3 \% . \mathrm{Si}_{3} \mathrm{~N}_{4}$ is characterized by its high strength over a wide temperature range, high fracture toughness, high hardness, excellent wear resistance, high thermal resistance and good chemical resistance, high shock, and thermal resistance. Balls were different only in diameter. Other balls' characteristics were identical: sphericity $99.9995 \%$, density $3.27 \mathrm{~g} / \mathrm{cm}^{3}$, elastic modulus $310 \mathrm{GPa}$, Poisson's ratio 0.24, hardness $78 \mathrm{HRC}$, thermal conductivity $29 \mathrm{~W} / \mathrm{mK}$, coefficient of thermal expansion $3.3 \times 10^{-6}{ }^{\circ} \mathrm{C}$, compressive strength $4055 \mathrm{MPa}$, maximum surface roughness $0.025 \mu \mathrm{m}$, diameter tolerance $0.5 \mu \mathrm{m}$, and sphericity tolerance $0.25 \mu \mathrm{m}$.

The surface roughness was measured before and after the experimental research. The measurement was performed on a Talysurf 6 measuring device with a diamond ball stylus, stylus radius $2 \mu \mathrm{m}$, stylus force $1 \mathrm{mN}$, and traverse speed $0.5 \mathrm{~mm} / \mathrm{s}$. The measurement was 
conducted with a cut-off length of $0.8 \mathrm{~mm}$ (Gaussian filter), a sampling length of $0.8 \mathrm{~mm}$, and an evaluation length of $4 \mathrm{~mm}$. Surface roughness values were calculated as mean values derived from five repeated measurements.

The workpiece surfaces treated with ball burnishing were pre-treated to the values of the arithmetic mean deviation of roughness profile $R a=3 \mu \mathrm{m}, 4 \mu \mathrm{m}, 5 \mu \mathrm{m}$ (the initial surface roughness). For these values of $R a$, the following values of maximum profile peak height $R p=12.05 \mu \mathrm{m}, 16.31 \mu \mathrm{m}$, and $19.59 \mu \mathrm{m}$, maximum profile valley depth $R v=11.75 \mu \mathrm{m}$, $15.96 \mu \mathrm{m}, 20.06 \mu \mathrm{m}$, and the maximum height of roughness profile $R z=23.8 \mu \mathrm{m}, 32.27 \mu \mathrm{m}$, and $39.65 \mu \mathrm{m}$ were obtained, respectively.

After the experiments, the ball burnishing process was modeled with the help of RA, ANN, and SVR. These three methods were used to predict the output variable-the final surface roughness $(R a)$. The theoretical foundations of these methods are presented below.

\subsection{Regression Modelling}

Regression modeling is a procedure by which statistical processing and analysis of experimental data give mathematical dependencies between the output and input variables, often using the method of least squares. This way, regression models are obtained, which, if there are two or more input variables, can be represented graphically using the response surface. It is best when the lowest order polynomial response surface can be obtained, i.e., one should not strive for an overly complex model of the higher-order. Models can be used to predict output variables for determining the values of input variables. They can also be a starting point or a basis for optimization, especially for optimizing the parameters of technological processes. The application of this method also indicates which of the input variables have a significant effect on the output variables.

For the derived regression model, it is necessary to carry out an analysis of variance and obtain significant statistics, e.g., mean, standard deviation, coefficient of variation, as well as ordinary, adjusted, and prediction coefficients of determination. Furthermore, the obtained model was analyzed graphically by the use of the following plots:

- Normal probability plot of residuals;

- Residuals versus input variables;

- Residuals versus predicted values;

- Residuals versus run.

The comparison of actual and predicted values calculated by the model is also significant.

\subsection{Artificial Neural Networks}

Artificial Neural Network (ANN) is a machine learning tool consisting of multiprocessing elements called neurons. Neurons in ANNs are divided into an input layer, one or more hidden layers, and an output layer. Neurons are connected through interconnection weight coefficients, so the structure of ANN mimics the actual biological neural network. The number of hidden layers and the number of neurons in each hidden layer are problem-dependent.

ANNs are widely used in various applications, such as pattern recognition, classification, regression, time series prediction, etc. When used in regression problems, the architecture of ANN is usually a feed-forward multilayer perceptron, which means that signals are transmitted through the network only in one direction, from input to output layer [68]. The main task of such a network is to determine the relationship between input and output data, i.e., to substitute a classical mathematical regression function.

For the given training dataset $\left\{\left(x_{i}, y_{i}\right)\right\}_{i=1}^{\mathrm{N}} \in \mathrm{R}^{\mathrm{m}} \times \mathrm{R}$, where $x_{i}$ is some $m$-dimensional input vector and $y_{i}$ is the corresponding output value, the weights in ANN need to be adjusted to obtain minimum output error compared to the training dataset. The process of weight adjustment is referred to as network training, and it is conducted using one of the optimization techniques (backpropagation, gradient descent, scaled conjugate gradient, 
Levenberg-Marquardt, Gaus-Newton, genetic algorithm, etc.) [69]. Once the network is trained, it can be used to obtain output values for any set of input parameter values.

\subsection{Support Vector Regression}

Support Vector Machines (SVM) is a very popular and powerful supervised machine learning technique used mostly to solve classification problems in a wide range of applications in various domains. However, SVMs can also be successfully applied to regression problems. In that case, they are commonly referred to as Support Vector Regression (SVR). The main advantages of SVR are their generalization ability, obtained by maximization of data margin, and the efficient learning of nonlinear functions by using kernel trick [70].

SVR is a technique of estimation of a linear function $F$ that maps input data to a real number based on the provided training dataset $\left\{\left(x_{i}, y_{i}\right)\right\}_{i=1}^{\mathrm{N}} \in \mathrm{R}^{\mathrm{m}} \times \mathrm{R}$. This function can be written as:

$$
F(x)=w \cdot x+b,
$$

where $w$ is the vector of appropriate weights and $b$ is the bias. The main task is to determine optimal values of these parameters to obtain an accurate regression model, i.e., to provide an accurate approximation of the training dataset by function $F(x)$. Instead of trying to determine the regression function, which minimizes the error of the training dataset, as with most mathematical regression techniques, SVR tries to maximize the margin around the function $F$, which envelops the training data, considering the constraints that approximation error must be less than some specified value $\varepsilon$. In other words, SVR solves the following optimization problem:

$$
\begin{gathered}
\text { maximize: } L_{m}(w)=\frac{1}{\|w\| \mid} \text {, i.e., minimize } L(w)=\frac{1}{2}|| w||^{2} \\
\text { subject to }:\left|y_{i}-w \cdot x_{i}-b\right| \leq \varepsilon \quad \forall\left(x_{i}, y_{i}\right) \in D
\end{gathered}
$$

where $L_{m}$ is the actual margin width, and $L$ is the alternative optimization criterion, which is more convenient for calculation. This optimization problem is usually solved by the method of Lagrange multipliers [69] in order to obtain optimal parameters $w$ and $b$.

The above-explained SVR method is the simplest one, implying that all training data fall into " $\varepsilon$-tube". In general, some of the data will fall outside the $\varepsilon$ boundary. These deviations need to be minimized, which is obtained using slack variables $\xi_{i}$ for any data value falling outside of $\varepsilon$. In this case, the optimization problem is modified in the following way:

$$
\begin{gathered}
\text { minimize }: L(w)=\frac{1}{2}|| w||^{2}+C \sum_{i=1}^{N} \xi_{i} \\
\text { subject to : }\left|y_{i}-w \cdot x_{i}-b\right| \leq \varepsilon+\xi_{i}, \quad \forall\left(x_{i}, y_{i}\right) \in D, \xi_{i} \geq 0,
\end{gathered}
$$

where $\xi_{i}$ represents the deviation of the predefined error limit $\varepsilon$, and $C$ represents the adjustable penalty parameter. This extended SVR model is called soft margin SVR, which is explained in more detail in [69].

The graphical representation of the SVR problem with one-dimensional input vector $x$ is depicted in Figure 2.

If the regression function is nonlinear, which is a common case, SVR can still be used applying the kernel trick, meaning that some kernel function $\Phi(x)$ is used to transform the original $\mathrm{m}$-dimensional feature space to some more-dimensional space in which the regression function is linear so that all previous considerations can be applied. The most common kernel functions are polynomial, Radial Basis Function (RBF), sigmoid, etc. [69]. 
After the RA, ANN, and SVR modeling processes, the actual (measured) $R a$ values were compared with the predicted values. The comparison between the measured and predicted $R a$ values were made based on the following equations:

$$
\begin{gathered}
P E_{R A_{i}, A N N_{i}, S V R_{i}}=\frac{\left|R a_{i p v}-R a_{i m v}\right|}{x_{i m v}} \cdot 100 \%, \\
M P E_{R A, A N N, S V R}=\frac{100 \%}{n} \sum_{i=1}^{n}\left|\frac{R a_{i p v}-R a_{i m v}}{R a_{i m v}}\right|,
\end{gathered}
$$

where $R a_{i m v}$ represents measured $R a$ value, $R a_{i p v}$ is the predicted $R a$ value, $P E$ is the percentage error, $M P E$ is the mean percentage error.

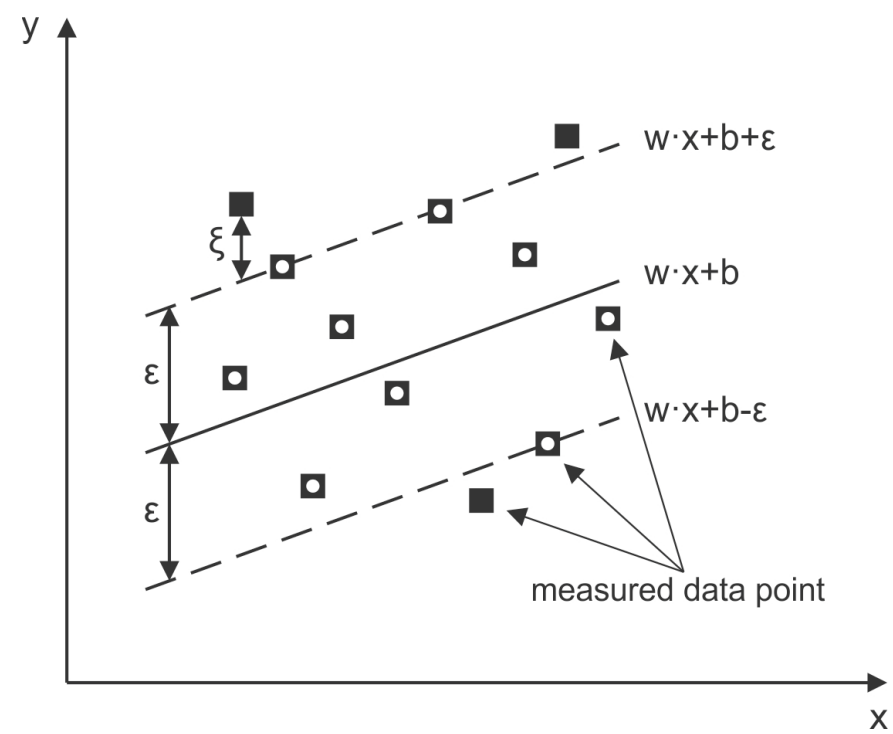

Figure 2. SVR problem with one-dimensional input.

\section{Results}

Experimental studies were conducted following a randomized full factorial experiment that allows the investigation of all combinations of input variable levels. Two experiments were conducted; the first one, named training experiment, was used for models obtaining, and the second one, named confirmation experiment, was used to examine the accuracy of models formed and trained on data from the training experiment. The structure of inputs and outputs was the same for both experiments.

\subsection{Training Experiment}

During the training experimental research, four processing parameters (input variables) were varied at the following levels:

- $\quad$ The depth of ball penetration $-a_{p}=8,12,16,20,24$ ( $\left.\mu \mathrm{m}\right)$;

- The initial surface roughness- $R a_{1}=3,4,5(\mu \mathrm{m})$;

- $\quad$ Burnishing feed- $f_{b}=0.1,0.2,0.3(\mathrm{~mm})$;

- Burnishing ball diameter- $D_{b}=6,8,10(\mathrm{~mm})$.

By considering the adopted levels of input variables, a total of $5 \times 3 \times 3 \times 3=135$ experiments were conducted within the training experiment. The measured values of the surface roughness are presented in Table 3.

Figure 3 provides a graphical representation of the measured data presented in Table 3. The value of output parameter $R a_{2}$ is depicted, related to pairs of input parameters, i.e., $R a_{1}$ $a_{p}, R a_{1}-f_{b}$, and $R a_{1}-D_{b}$, respectively. The experimental data were approximated by a surface, obtained using cubic interpolation among all 135 data in Matlab's Curve Fitting Toolbox 
(MathWorks, Matlab version 2017b). The cubic interpolation method constructs the surface interpolating experimental data by bicubic interpolation function using the least-squares method. In comparison to the other two commonly used two-dimensional interpolation techniques, bilinear and nearest-neighbor methods, cubic interpolation obtains a smoother surface, which provides a more intuitive interpretation of experimental data [71].

Table 3. The measured values of the surface roughness.

\begin{tabular}{|c|c|c|c|c|c|c|c|c|c|c|c|c|c|c|c|c|c|}
\hline Run & $\begin{array}{c}a_{p} \\
(\mu \mathrm{m})\end{array}$ & $\begin{array}{l}R a_{1} \\
(\mu \mathrm{m})\end{array}$ & $\stackrel{f_{b}}{(\mathbf{m m})}$ & $\begin{array}{c}D_{b} \\
(\mathrm{~mm})\end{array}$ & $\begin{array}{c}R a_{2} \\
\text { Measured } \\
(\mu \mathrm{m})\end{array}$ & Run & $\begin{array}{c}a_{p} \\
(\mu \mathrm{m})\end{array}$ & $\begin{array}{l}R a_{1} \\
(\mu \mathrm{m})\end{array}$ & $\stackrel{f_{b}}{(\mathbf{m m})}$ & $\begin{array}{c}D_{b} \\
(\mathrm{~mm})\end{array}$ & $\underset{\substack{\text { Measured } \\
(\mu \mathrm{m})}}{R a_{2}}$ & Run & $\begin{array}{c}a_{p} \\
(\mu \mathrm{m})\end{array}$ & $\begin{array}{l}R a_{1} \\
(\mu \mathrm{m})\end{array}$ & $\stackrel{f_{b}}{(\mathrm{~mm})}$ & $\begin{array}{c}D_{b} \\
(\mathrm{~mm})\end{array}$ & $\begin{array}{c}R a_{2} \\
\text { Measured } \\
(\mu \mathrm{m})\end{array}$ \\
\hline 1 & 12 & 5 & 0.3 & 8 & 3.02 & 46 & 8 & 4 & 0.3 & 6 & 3.23 & 91 & 8 & 5 & 0.3 & 8 & 4.05 \\
\hline 2 & 24 & 3 & 0.2 & 10 & 3.38 & 47 & 16 & 4 & 0.2 & 10 & 0.37 & 92 & 8 & 5 & 0.1 & 10 & 3.12 \\
\hline 3 & 24 & 5 & 0.3 & 8 & 1.97 & 48 & 24 & 3 & 0.2 & 6 & 3.81 & 93 & 16 & 4 & 0.3 & 10 & 0.87 \\
\hline 4 & 24 & 4 & 0.3 & 10 & 2.87 & 49 & 8 & 4 & 0.2 & 10 & 2.35 & 94 & 20 & 5 & 0.1 & 8 & 0.13 \\
\hline 5 & 24 & 3 & 0.1 & 6 & 3.53 & 50 & 20 & 5 & 0.1 & 6 & 0.15 & 95 & 16 & 4 & 0.1 & 10 & 0.13 \\
\hline 6 & 24 & 5 & 0.2 & 6 & 1.57 & 51 & 8 & 3 & 0.2 & 10 & 1.37 & 96 & 16 & 5 & 0.1 & 8 & 1.16 \\
\hline 7 & 12 & 5 & 0.3 & 6 & 3.24 & 52 & 20 & 4 & 0.1 & 10 & 1.13 & 97 & 8 & 3 & 0.2 & 8 & 1.44 \\
\hline 8 & 24 & 4 & 0.2 & 8 & 2.49 & 53 & 16 & 3 & 0.1 & 6 & 1.27 & 98 & 24 & 3 & 0.3 & 8 & 4.07 \\
\hline 9 & 16 & 4 & 0.1 & 6 & 0.14 & 54 & 16 & 3 & 0.2 & 6 & 1.55 & 99 & 12 & 4 & 0.1 & 6 & 1.27 \\
\hline 10 & 20 & 5 & 0.2 & 6 & 0.41 & 55 & 12 & 5 & 0.1 & 10 & 2.15 & 100 & 12 & 3 & 0.2 & 10 & 0.38 \\
\hline 11 & 20 & 3 & 0.2 & 8 & 2.49 & 56 & 16 & 5 & 0.1 & 6 & 1.28 & 101 & 12 & 3 & 0.2 & 6 & 0.42 \\
\hline 12 & 12 & 5 & 0.1 & 6 & 2.4 & 57 & 16 & 3 & 0.3 & 10 & 1.87 & 102 & 16 & 3 & 0.3 & 6 & 2.13 \\
\hline 13 & 20 & 3 & 0.2 & 10 & 2.38 & 58 & 8 & 5 & 0.1 & 6 & 3.52 & 103 & 20 & 4 & 0.2 & 6 & 1.57 \\
\hline 14 & 24 & 5 & 0.3 & 6 & 2.14 & 59 & 8 & 3 & 0.3 & 8 & 1.97 & 104 & 20 & 4 & 0.2 & 10 & 1.37 \\
\hline 15 & 8 & 3 & 0.1 & 10 & 1.15 & 60 & 12 & 4 & 0.2 & 10 & 1.38 & 105 & 24 & 4 & 0.1 & 6 & 2.42 \\
\hline 16 & 20 & 3 & 0.3 & 8 & 3.04 & 61 & 20 & 5 & 0.3 & 10 & 0.87 & 106 & 8 & 4 & 0.1 & 8 & 2.23 \\
\hline 17 & 8 & 4 & 0.2 & 6 & 2.69 & 62 & 16 & 3 & 0.1 & 8 & 1.16 & 107 & 20 & 4 & 0.3 & 6 & 2.12 \\
\hline 18 & 24 & 4 & 0.1 & 10 & 2.15 & 63 & 12 & 5 & 0.2 & 8 & 2.47 & 108 & 8 & 5 & 0.2 & 6 & 3.83 \\
\hline 19 & 16 & 4 & 0.1 & 8 & 0.13 & 64 & 20 & 3 & 0.1 & 6 & 2.41 & 109 & 24 & 4 & 0.3 & 6 & 3.24 \\
\hline 20 & 24 & 5 & 0.2 & 8 & 1.42 & 65 & 8 & 4 & 0.3 & 8 & 3.02 & 110 & 8 & 4 & 0.3 & 10 & 2.88 \\
\hline 21 & 12 & 3 & 0.3 & 6 & 0.99 & 66 & 12 & 4 & 0.1 & 10 & 1.14 & 111 & 8 & 3 & 0.3 & 10 & 1.86 \\
\hline 22 & 20 & 5 & 0.2 & 10 & 0.35 & 67 & 12 & 5 & 0.2 & 6 & 2.67 & 112 & 20 & 3 & 0.3 & 10 & 2.86 \\
\hline 23 & 12 & 3 & 0.1 & 6 & 0.14 & 68 & 16 & 5 & 0.2 & 6 & 1.56 & 113 & 12 & 5 & 0.3 & 10 & 2.87 \\
\hline 24 & 20 & 4 & 0.1 & 6 & 1.26 & 69 & 8 & 3 & 0.1 & 8 & 1.18 & 114 & 8 & 3 & 0.1 & 6 & 1.26 \\
\hline 25 & 12 & 5 & 0.2 & 10 & 2.36 & 70 & 16 & 5 & 0.2 & 8 & 1.43 & 115 & 20 & 3 & 0.1 & 10 & 2.13 \\
\hline 26 & 20 & 4 & 0.1 & 8 & 1.19 & 71 & 16 & 4 & 0.3 & 8 & 0.91 & 116 & 24 & 4 & 0.2 & 6 & 2.66 \\
\hline 27 & 8 & 4 & 0.1 & 10 & 2.11 & 72 & 24 & 5 & 0.1 & 10 & 1.11 & 117 & 24 & 3 & 0.2 & 8 & 3.54 \\
\hline 28 & 20 & 5 & 0.3 & 6 & 0.97 & 73 & 8 & 5 & 0.1 & 8 & 3.28 & 118 & 24 & 4 & 0.2 & 10 & 2.37 \\
\hline 29 & 12 & 5 & 0.1 & 8 & 2.25 & 74 & 8 & 3 & 0.3 & 6 & 2.12 & 119 & 24 & 3 & 0.3 & 10 & 3.87 \\
\hline 30 & 16 & 3 & 0.1 & 10 & 1.13 & 75 & 8 & 5 & 0.3 & 6 & 4.39 & 120 & 16 & 5 & 0.1 & 10 & 1.14 \\
\hline 31 & 12 & 4 & 0.3 & 6 & 2.14 & 76 & 24 & 5 & 0.3 & 10 & 1.86 & 121 & 20 & 4 & 0.2 & 8 & 1.43 \\
\hline 32 & 12 & 4 & 0.2 & 6 & 1.54 & 77 & 24 & 4 & 0.1 & 8 & 2.24 & 122 & 16 & 4 & 0.2 & 8 & 0.38 \\
\hline 33 & 24 & 3 & 0.3 & 6 & 4.38 & 78 & 24 & 5 & 0.1 & 8 & 1.17 & 123 & 24 & 3 & 0.1 & 10 & 3.13 \\
\hline 34 & 16 & 5 & 0.3 & 8 & 1.94 & 79 & 16 & 4 & 0.3 & 6 & 0.98 & 124 & 24 & 5 & 0.1 & 6 & 1.26 \\
\hline 35 & 12 & 3 & 0.1 & 8 & 0.15 & 80 & 8 & 4 & 0.1 & 6 & 2.42 & 125 & 20 & 5 & 0.1 & 10 & 0.13 \\
\hline 36 & 16 & 5 & 0.2 & 10 & 1.36 & 81 & 16 & 4 & 0.2 & 6 & 0.42 & 126 & 8 & 5 & 0.3 & 10 & 3.86 \\
\hline 37 & 8 & 3 & 0.2 & 6 & 1.55 & 82 & 20 & 3 & 0.2 & 6 & 2.68 & 127 & 16 & 3 & 0.3 & 8 & 1.99 \\
\hline 38 & 8 & 5 & 0.2 & 10 & 3.37 & 83 & 20 & 5 & 0.3 & 8 & 0.9 & 128 & 12 & 3 & 0.1 & 10 & 0.13 \\
\hline 39 & 24 & 4 & 0.3 & 8 & 3.04 & 84 & 12 & 3 & 0.2 & 8 & 0.39 & 129 & 12 & 3 & 0.3 & 10 & 0.89 \\
\hline 40 & 20 & 5 & 0.2 & 8 & 0.37 & 85 & 20 & 3 & 0.3 & 6 & 3.25 & 130 & 8 & 5 & 0.2 & 8 & 3.54 \\
\hline 41 & 20 & 4 & 0.3 & 10 & 1.88 & 86 & 16 & 3 & 0.2 & 10 & 1.36 & 131 & 12 & 4 & 0.1 & 8 & 1.19 \\
\hline 42 & 16 & 5 & 0.3 & 6 & 2.14 & 87 & 24 & 3 & 0.1 & 8 & 3.27 & 132 & 8 & 4 & 0.2 & 8 & 2.48 \\
\hline 43 & 12 & 3 & 0.3 & 8 & 0.92 & 88 & 12 & 4 & 0.2 & 8 & 1.44 & 133 & 24 & 5 & 0.2 & 10 & 1.37 \\
\hline 44 & 16 & 3 & 0.2 & 8 & 1.45 & 89 & 12 & 4 & 0.3 & 8 & 1.96 & 134 & 16 & 5 & 0.3 & 10 & 1.85 \\
\hline 45 & 12 & 4 & 0.3 & 10 & 1.87 & 90 & 20 & 4 & 0.3 & 8 & 1.96 & 135 & 20 & 3 & 0.1 & 8 & 2.23 \\
\hline
\end{tabular}
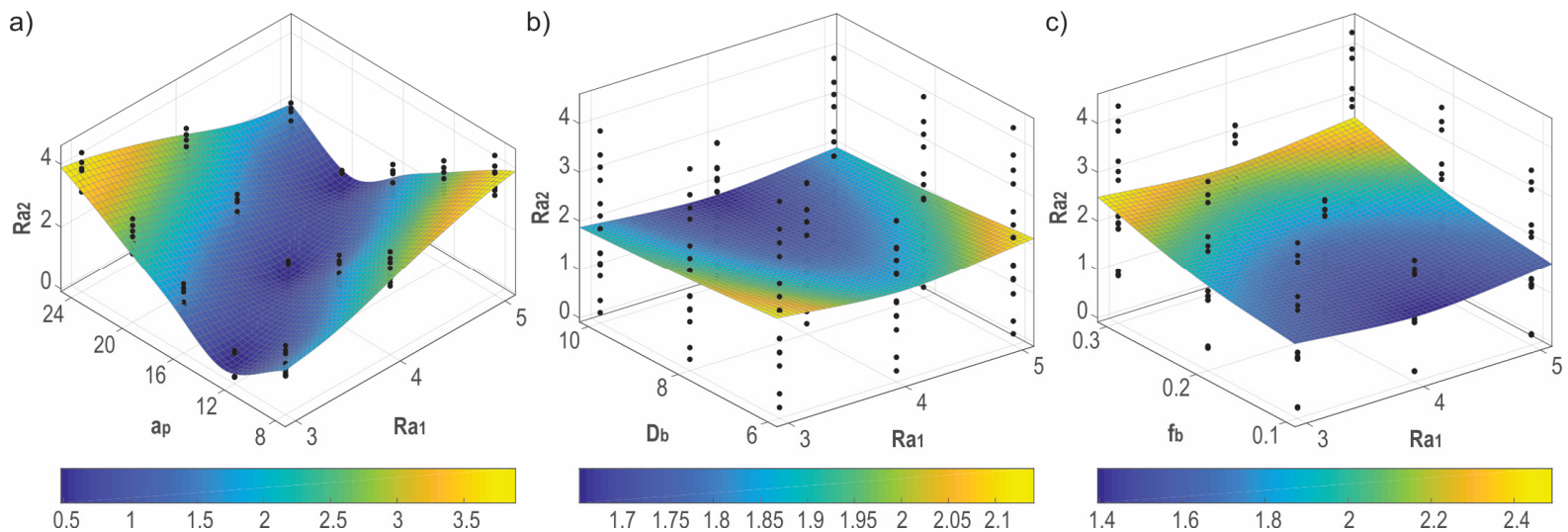

Figure 3. Graphical representation of the measured data presented in Table 3 (a) pair of input parameters $R a_{1}-a_{p}$; (b) pair of input parameters $R a_{1}-D_{b}$; (c) pair of input parameters $R a_{1}-f_{b}$. 
Based on the statistical processing of the experimental data, using the Design Expert software (Stat-Ease, Inc., Design Expert version DX8, 8.0.7.1), a regression model was obtained. It was then transformed and reduced. The analysis of variance of the obtained regression model is presented in Table 4 . Table 4 also shows other useful information. The ordinary coefficient of determination $R^{2}$ is close to 1 , as well as its variations, $R^{2}$ adjusted and $R^{2}$ for prediction.

Table 4. ANOVA for Response Surface Reduced Quadratic Model.

\begin{tabular}{|c|c|c|c|c|c|}
\hline Source & $\begin{array}{l}\text { Sum of } \\
\text { Squares }\end{array}$ & $\begin{array}{l}\text { Degrees of } \\
\text { Freedom }\end{array}$ & $\begin{array}{l}\text { Mean } \\
\text { Square }\end{array}$ & F Value & $\begin{array}{l}p \text {-Value } \\
\text { Prob }>\text { F }\end{array}$ \\
\hline Model & 850.34 & 8 & 106.29 & 386.46 & $<0.0001$ \\
\hline A-Depth of ball penetration & $5.16 \times 10^{-4}$ & 1 & $5.16 \times 10^{-4}$ & $1.87 \times 10^{-3}$ & 0.9655 \\
\hline B-Initial surface roughness & $2.79 \times 10^{-3}$ & 1 & $2.79 \times 10^{-3}$ & 0.010 & 0.9199 \\
\hline C-Burnishing feed & 74.02 & 1 & 74.02 & 269.13 & $<0.0001$ \\
\hline D_-Burnishing ball diameter & 9.21 & 1 & 9.21 & 33.48 & $<0.0001$ \\
\hline $\mathrm{AB}$ & 474.82 & 1 & 474.82 & 1726.34 & $<0.0001$ \\
\hline$A^{2}$ & 274.64 & 1 & 274.64 & 998.55 & $<0.0001$ \\
\hline $\mathrm{B}^{2}$ & 13.43 & 1 & 13.43 & 48.84 & $<0.0001$ \\
\hline$C^{2}$ & 4.21 & 1 & 4.21 & 15.32 & 0.0001 \\
\hline Residual & 34.66 & 126 & 0.28 & & \\
\hline$R^{2}$ & 0.9608 & \multicolumn{2}{|c|}{ Standard Deviation } & \multicolumn{2}{|c|}{0.52} \\
\hline$R^{2}$ adjusted & 0.9584 & \multicolumn{2}{|c|}{ Mean } & \multicolumn{2}{|c|}{3.21} \\
\hline$R^{2}$ for prediction & 0.9550 & \multicolumn{2}{|c|}{ Coefficient of Variation \% } & \multicolumn{2}{|c|}{16.33} \\
\hline Adequate Precision & 73.0790 & \multicolumn{2}{|c|}{ Predicted Residual Sum of Squares } & \multicolumn{2}{|c|}{39.83} \\
\hline
\end{tabular}

Regression model in terms of natural factors is as follows:

$$
\begin{gathered}
R a_{2}{ }^{1.6}=0.15013-0.080284 \cdot a_{p}+1.13779 \cdot R a_{1}-5.92032 \cdot f_{b}-0.15994 \cdot D_{b}-0.40604 \cdot a_{p} \cdot R a_{1} \\
+0.005327 \cdot a_{p}^{2}+0.66916 \cdot R a_{1}{ }^{2}+37.47329 \cdot f_{b}^{2}
\end{gathered}
$$

Figure 4 is a graphical representation of the significant interaction between the factors A-depth of ball penetration $\left(a_{p}\right)$ and B - the initial surface roughness $\left(R a_{1}\right)$, for burnishing feed of $0.15 \mathrm{~mm}$ and burnishing ball diameter of $6 \mathrm{~mm}$. These two factors, $\mathrm{A}$ and $\mathrm{B}$ are nonsignificant (Table 4), but their interaction is significant (Table 4), so they were added to the model after the backward elimination regression. It can be seen in Figure 4 that the different effects on the final surface roughness $\left(R a_{2}\right)$ for the smallest $(3 \mu \mathrm{m})$ and the largest $(5 \mu \mathrm{m})$ initial surface roughness is in the range of the depth of ball penetration from 12 to $20 \mu \mathrm{m}$. For the smallest initial surface roughness, with the increasing depth of ball penetration from $12 \mu \mathrm{m}$ to $20 \mu \mathrm{m}$, the final surface roughness also increases, while for the largest initial surface roughness, with the increasing depth of ball penetration from $12 \mu \mathrm{m}$ to $20 \mu \mathrm{m}$, the final surface roughness reduces. For the depth of ball penetration lower than $12 \mu \mathrm{m}$, the final surface roughness reduces for both the smallest and the largest initial surface roughness, while for the depth of ball penetration greater than $20 \mu \mathrm{m}$, the final surface roughness increases for both the smallest and the largest initial surface roughness.

Below, Figures 5-7 represent the normal probability plot of internally studentized residuals, plot of residuals versus $C$ (burnishing feed), and plot of residuals versus D (burnishing ball diameter), respectively.

Analysis of variance and the statistical parameters shown (Table 4), as well as Figures 5-7 above, indicate the adequacy of the regression model because the residuals are distributed normally (plot in Figure 5 resembles the straight line), and the internally studentized residuals are not higher than 3 or 4 standard deviations from zero and are quite structureless.

For modeling purposes of the burnishing process using ANN, input parameters were the depth of ball penetration, the initial surface roughness, burnishing feed, burnishing ball diameter, and the output was the predicted value of the final surface roughness. Two main characteristics must be defined for the ANN-its architecture and the training 
method used to optimize network weights. For the purposes of modeling, the most often used network type is a feed-forward multilayer perceptron network, which was also used in this study. The optimal architecture of the network was determined using the trial-and-error method, and it consists of three hidden layers with four, five, and four neurons, respectively (4-5-4 scheme), as shown in Figure 8. For neurons in the hidden layer, the sigmoid activation function is applied, while the neurons in the output layer are activated by the linear activation function, which is a common choice for feedforward multilayer perceptron ANNs used in regression purposes [72]. Three popular training methods were applied, i.e., Levenberg-Marquardt, Scaled Conjugate Gradient, and Resilient Backpropagation. Among these methods, Levenberg-Marquardt was chosen because it provided the best results [73]. The optimization criterion, Mean Square Error (MSE), was used, which is common in similar applications. The ANN was implemented using Matlab's Deep Learning Toolbox.
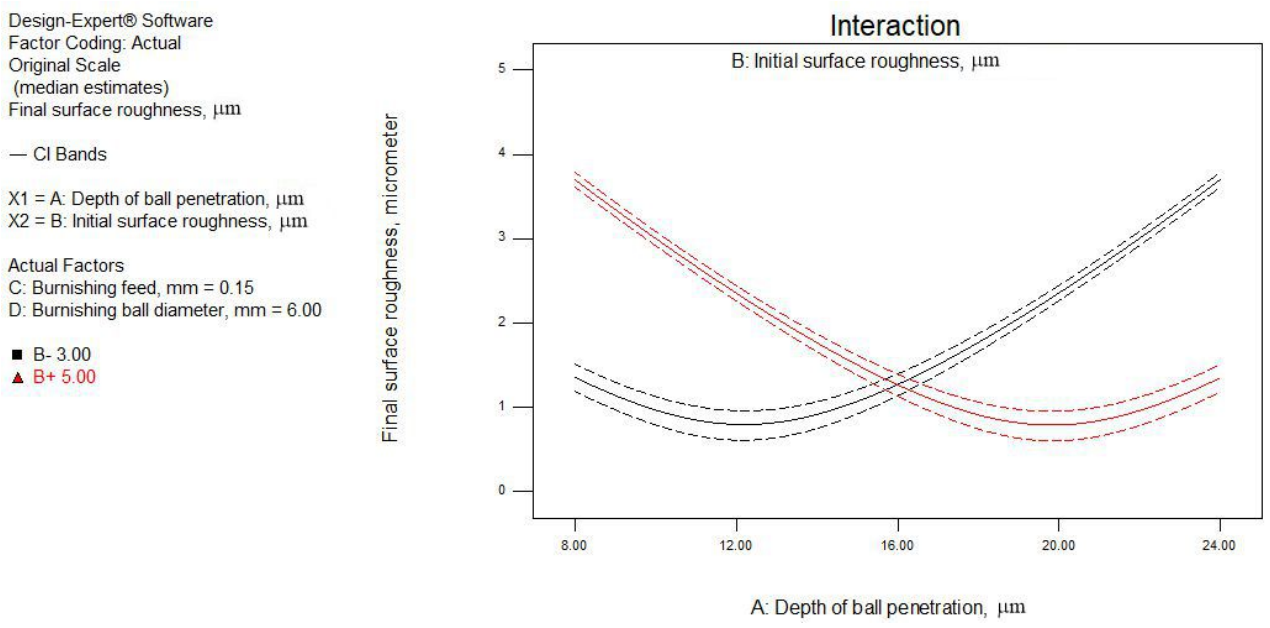

Figure 4. Interaction between factors A and B.
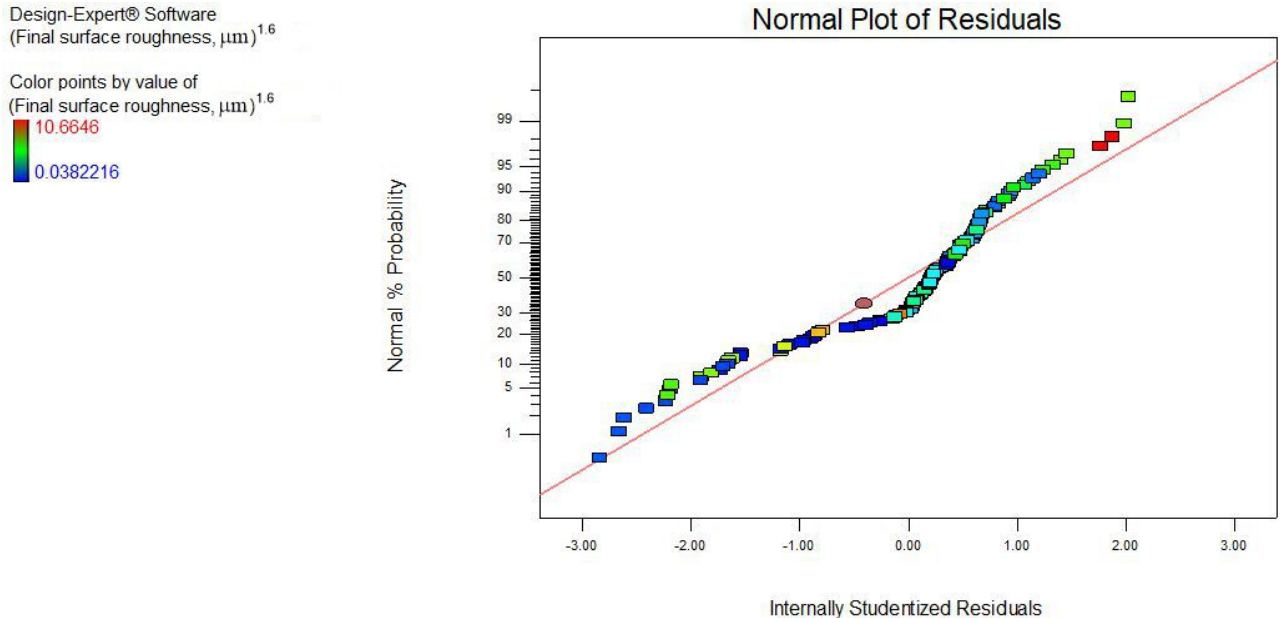

Figure 5. Normal probability plot of internally studentized residuals.

The available data set, consisting of 135 samples, was divided into three sets: the training set (95 randomly chosen data samples, which is approximately $70 \%$ of the whole data set), the validation set (20 samples, i.e., $15 \%$ ), and the testing set (20 samples, i.e., $15 \%$ ). The optimization of networks weights was conducted iteratively on the training data set, and results were verified using the validation set. When the error of the validation set reached the minimal value, the training was terminated to prevent overfitting, which is 
the standard procedure for ANN training. The test set was used to evaluate the quality of network prediction for the data that were not used in training.
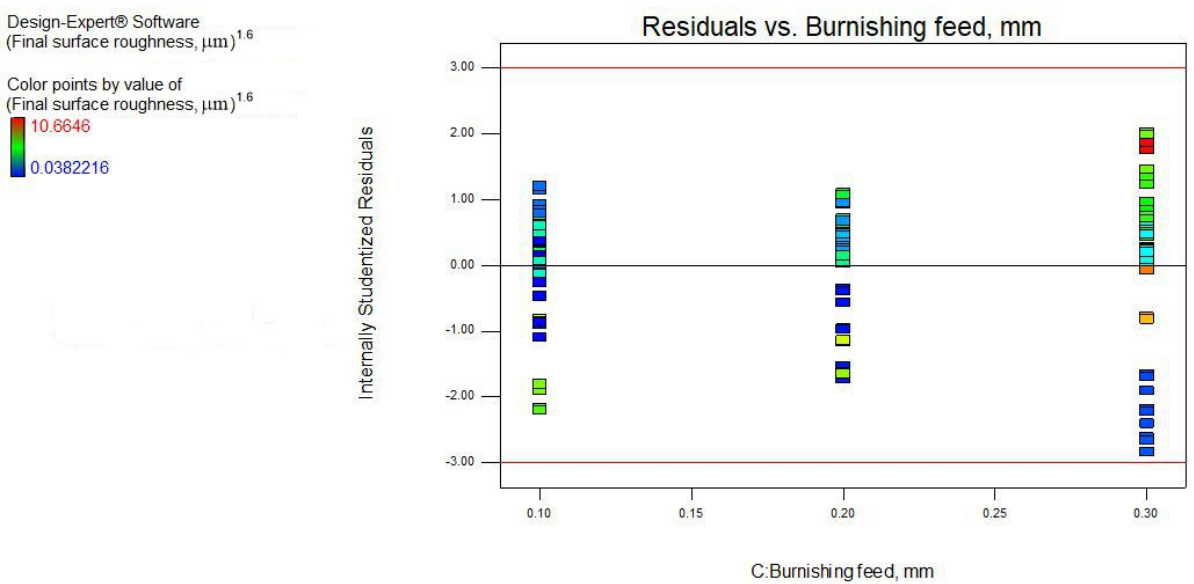

Figure 6. The plot of internally studentized residuals versus C (burnishing feed).
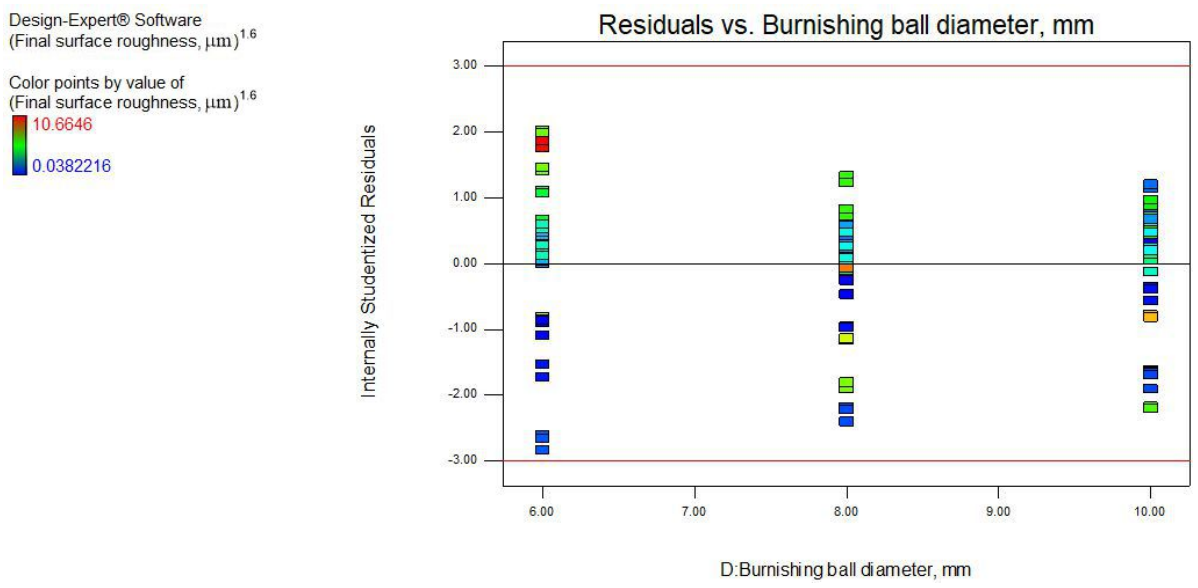

Figure 7. The plot of internally studentized residuals versus D (burnishing ball diameter).

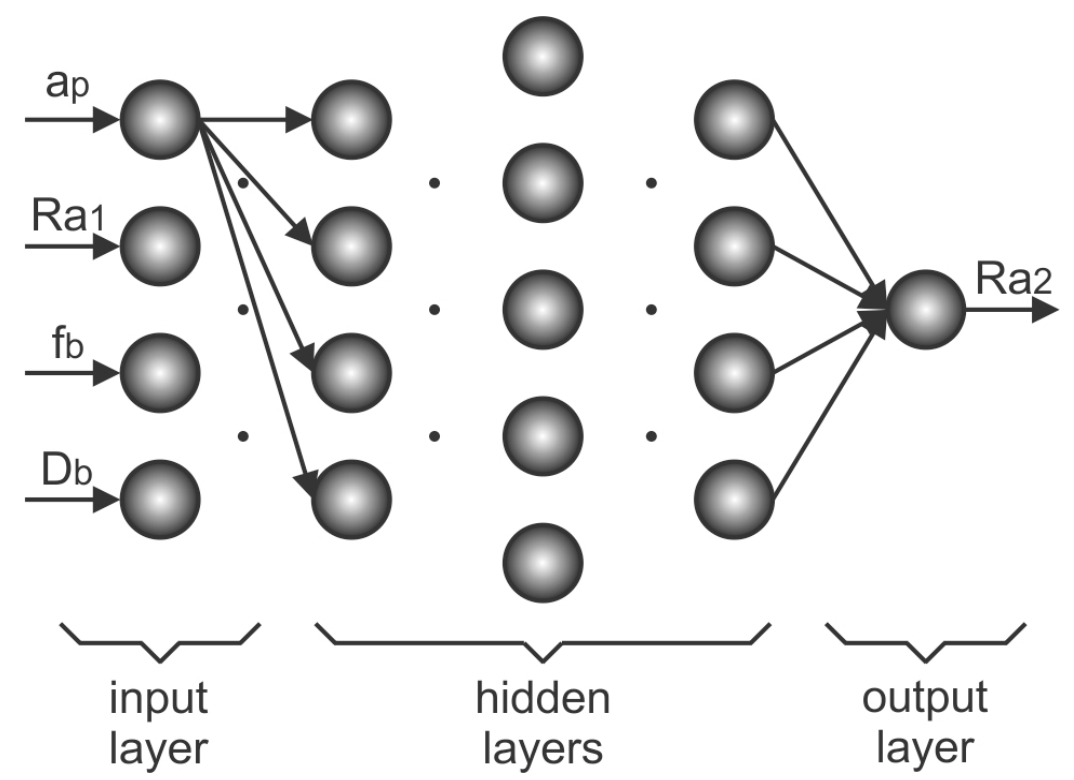

Figure 8. The architecture of the ANN applied for modeling. 
In the modeling of the burnishing process using SVR, the same inputs and outputs as with RA and ANN modeling were used. Matlab's Regression Learner Application was used for software implementation. In order to avoid overfitting, $k$-fold validation was applied as a standard statistical method to estimate the SVR quality. In this procedure, the experimental data set was divided into $k$ groups ( $k=5$ in this study), and a total of $k$ models were fitted using the optimization procedure explained in Section 2.3. Each of these models was formed by holding out one group and using the remaining $k-1$ group of data for the SVR training. The group of data that was held out is used to evaluate the SVR model since it represented the data "not seen" by the model. When all $k$ models were evaluated, the average efficiency was used as the estimation of the SVR model quality.

Besides the linear SVR, three different kernel functions were also applied to construct nonlinear SVR, namely quadratic, cubic, and Gaussian. The best results were obtained using the quadratic kernel function.

Table 5 shows all measured (actual), as well as regression (predicted) values and percentage errors (PE) calculated based on Equation (4).

Table 5. Measured and predicted values of the surface roughness and percentage errors for training experiment.

\begin{tabular}{|c|c|c|c|c|c|c|c|c|c|c|c|}
\hline \multirow[b]{2}{*}{ Run } & \multirow[b]{2}{*}{$\begin{array}{c}a_{p} \\
(\mu \mathrm{m})\end{array}$} & \multirow[b]{2}{*}{$\begin{array}{c}R a_{1} \\
(\mu \mathrm{m})\end{array}$} & \multirow[b]{2}{*}{$\begin{array}{c}f_{b} \\
(\mathrm{~mm})\end{array}$} & \multirow[b]{2}{*}{$\begin{array}{c}D_{b} \\
(\mathrm{~mm})\end{array}$} & \multirow[b]{2}{*}{$\begin{array}{c}R a_{2} \\
\text { Measured } \\
(\mu \mathrm{m})\end{array}$} & \multicolumn{2}{|c|}{ RA } & \multicolumn{2}{|c|}{ ANN } & \multicolumn{2}{|c|}{ SVR } \\
\hline & & & & & & $\begin{array}{c}R a_{2} \\
\text { Predicted } \\
(\mu \mathrm{m})\end{array}$ & $\begin{array}{l}P E \\
(\%)\end{array}$ & $\begin{array}{c}R a_{2} \\
\text { Predicted } \\
(\mu \mathrm{m})\end{array}$ & $\begin{array}{l}P E \\
(\%)\end{array}$ & $\begin{array}{c}R a_{2} \\
\text { Predicted } \\
(\mu \mathrm{m})\end{array}$ & $\begin{array}{l}P E \\
(\%)\end{array}$ \\
\hline 1 & 12 & 5 & 0.3 & 8 & 3.02 & 2.813 & 6.868 & 3.028 & 0.272 & 3.013 & 0.244 \\
\hline 2 & 24 & 3 & 0.2 & 10 & 3.38 & 3.618 & 7.039 & 3.373 & 0.207 & 3.413 & 0.980 \\
\hline 3 & 24 & 5 & 0.3 & 8 & 1.97 & 1.954 & 0.833 & 1.984 & 0.694 & 1.991 & 1.050 \\
\hline 4 & 24 & 4 & 0.3 & 10 & 2.87 & 2.797 & 2.543 & 2.860 & 0.364 & 2.859 & 0.376 \\
\hline 5 & 24 & 3 & 0.1 & 6 & 3.53 & 3.649 & 3.369 & 3.522 & 0.237 & 3.471 & 1.671 \\
\hline 6 & 24 & 5 & 0.2 & 6 & 1.57 & 1.522 & 3.067 & 1.542 & 1.811 & 1.558 & 0.791 \\
\hline 7 & 12 & 5 & 0.3 & 6 & 3.24 & 2.919 & 9.911 & 3.247 & 0.204 & 3.226 & 0.422 \\
\hline 8 & 24 & 4 & 0.2 & 8 & 2.49 & 2.460 & 1.190 & 2.497 & 0.275 & 2.585 & 3.825 \\
\hline 9 & 16 & 4 & 0.1 & 6 & 0.14 & 0.725 & 418.053 & 0.151 & 7.645 & 0.146 & 4.120 \\
\hline 10 & 20 & 5 & 0.2 & 6 & 0.41 & 1.015 & 147.471 & 0.406 & 0.877 & 0.390 & 4.999 \\
\hline 11 & 20 & 3 & 0.2 & 8 & 2.49 & 2.365 & 5.033 & 2.493 & 0.116 & 2.547 & 2.306 \\
\hline 12 & 12 & 5 & 0.1 & 6 & 2.4 & 2.279 & 5.025 & 2.414 & 0.597 & 2.334 & 2.738 \\
\hline 13 & 20 & 3 & 0.2 & 10 & 2.38 & 2.244 & 5.735 & 2.356 & 0.994 & 2.409 & 1.219 \\
\hline 14 & 24 & 5 & 0.3 & 6 & 2.14 & 2.085 & 2.582 & 2.143 & 0.140 & 2.132 & 0.373 \\
\hline 15 & 8 & 3 & 0.1 & 10 & 1.15 & 0.864 & 24.859 & 1.132 & 1.540 & 1.106 & 3.804 \\
\hline 16 & 20 & 3 & 0.3 & 8 & 3.04 & 2.817 & 7.327 & 3.037 & 0.085 & 3.016 & 0.800 \\
\hline 17 & 8 & 4 & 0.2 & 6 & 2.69 & 2.573 & 4.339 & 2.661 & 1.063 & 2.749 & 2.194 \\
\hline 18 & 24 & 4 & 0.1 & 10 & 2.15 & 2.137 & 0.599 & 2.140 & 0.485 & 2.133 & 0.791 \\
\hline 19 & 16 & 4 & 0.1 & 8 & 0.13 & 0.450 & 245.818 & 0.136 & 4.453 & 0.139 & 7.125 \\
\hline 20 & 24 & 5 & 0.2 & 8 & 1.42 & 1.361 & 4.134 & 1.443 & 1.619 & 1.451 & 2.215 \\
\hline 21 & 12 & 3 & 0.3 & 6 & 0.99 & 1.689 & 70.622 & 0.991 & 0.112 & 1.027 & 3.735 \\
\hline 22 & 20 & 5 & 0.2 & 10 & 0.35 & 0.550 & 57.028 & 0.355 & 1.424 & 0.345 & 1.424 \\
\hline 23 & 12 & 3 & 0.1 & 6 & 0.14 & 0.648 & 362.997 & 0.152 & 8.440 & 0.145 & 3.809 \\
\hline 24 & 20 & 4 & 0.1 & 6 & 1.26 & 1.262 & 0.194 & 1.274 & 1.089 & 1.246 & 1.098 \\
\hline 25 & 12 & 5 & 0.2 & 10 & 2.36 & 2.238 & 5.163 & 2.355 & 0.221 & 2.405 & 1.910 \\
\hline 26 & 20 & 4 & 0.1 & 8 & 1.19 & 1.081 & 9.193 & 1.190 & 0.033 & 1.178 & 0.978 \\
\hline 27 & 8 & 4 & 0.1 & 10 & 2.11 & 2.135 & 1.181 & 2.103 & 0.355 & 2.138 & 1.317 \\
\hline 28 & 20 & 5 & 0.3 & 6 & 0.97 & 1.685 & 73.746 & 0.966 & 0.425 & 0.946 & 2.455 \\
\hline 29 & 12 & 5 & 0.1 & 8 & 2.25 & 2.155 & 4.204 & 2.246 & 0.197 & 2.230 & 0.869 \\
\hline 30 & 16 & 3 & 0.1 & 10 & 1.13 & 0.752 & 33.495 & 1.117 & 1.167 & 1.117 & 1.124 \\
\hline 31 & 12 & 4 & 0.3 & 6 & 2.14 & 2.094 & 2.143 & 2.125 & 0.693 & 2.076 & 3.009 \\
\hline 32 & 12 & 4 & 0.2 & 6 & 1.54 & 1.533 & 0.442 & 1.545 & 0.340 & 1.545 & 0.355 \\
\hline
\end{tabular}


Table 5. Cont.

\begin{tabular}{|c|c|c|c|c|c|c|c|c|c|c|c|}
\hline \multirow[b]{2}{*}{ Run } & \multirow[b]{2}{*}{$\begin{array}{c}a_{p} \\
(\mu \mathrm{m})\end{array}$} & \multirow[b]{2}{*}{$\begin{array}{c}R a_{1} \\
(\mu \mathrm{m})\end{array}$} & \multirow[b]{2}{*}{$\underset{(\mathrm{mm})}{f_{b}}$} & \multirow[b]{2}{*}{$\begin{array}{c}D_{b} \\
(\mathrm{~mm})\end{array}$} & \multirow[b]{2}{*}{$\begin{array}{c}R a_{2} \\
\text { Measured } \\
(\mu \mathrm{m})\end{array}$} & \multicolumn{2}{|c|}{ RA } & \multicolumn{2}{|c|}{ ANN } & \multicolumn{2}{|c|}{ SVR } \\
\hline & & & & & & $\begin{array}{c}R a_{2} \\
\text { Predicted } \\
(\mu \mathrm{m})\end{array}$ & $\begin{array}{l}P E \\
(\%)\end{array}$ & $\begin{array}{c}R a_{2} \\
\text { Predicted } \\
(\mu \mathrm{m})\end{array}$ & $\begin{array}{l}P E \\
(\%)\end{array}$ & $\begin{array}{c}R a_{2} \\
\text { Predicted } \\
(\mu \mathrm{m})\end{array}$ & $\begin{array}{l}P E \\
(\%)\end{array}$ \\
\hline 33 & 24 & 3 & 0.3 & 6 & 4.38 & 4.150 & 5.250 & 4.192 & 4.301 & 4.360 & 0.467 \\
\hline 34 & 16 & 5 & 0.3 & 8 & 1.94 & 1.884 & 2.873 & 1.962 & 1.109 & 1.944 & 0.196 \\
\hline 35 & 12 & 3 & 0.1 & 8 & 0.15 & 0.342 & 128.156 & 0.137 & 8.584 & 0.144 & 4.193 \\
\hline 36 & 16 & 5 & 0.2 & 10 & 1.36 & 1.094 & 19.578 & 1.361 & 0.050 & 1.359 & 0.053 \\
\hline 37 & 8 & 3 & 0.2 & 6 & 1.55 & 1.525 & 1.640 & 1.545 & 0.353 & 1.548 & 0.122 \\
\hline 38 & 8 & 5 & 0.2 & 10 & 3.37 & 3.613 & 7.214 & 3.355 & 0.452 & 3.318 & 1.553 \\
\hline 39 & 24 & 4 & 0.3 & 8 & 3.04 & 2.904 & 4.485 & 3.046 & 0.197 & 3.031 & 0.296 \\
\hline 40 & 20 & 5 & 0.2 & 8 & 0.37 & 0.803 & 116.967 & 0.376 & 1.644 & 0.367 & 0.784 \\
\hline 41 & 20 & 4 & 0.3 & 10 & 1.88 & 1.828 & 2.748 & 1.877 & 0.137 & 1.828 & 2.768 \\
\hline 42 & 16 & 5 & 0.3 & 6 & 2.14 & 2.018 & 5.695 & 2.125 & 0.724 & 2.061 & 3.683 \\
\hline 43 & 12 & 3 & 0.3 & 8 & 0.92 & 1.539 & 67.299 & 0.936 & 1.743 & 0.959 & 4.205 \\
\hline 44 & 16 & 3 & 0.2 & 8 & 1.45 & 1.280 & 11.694 & 1.449 & 0.067 & 1.453 & 0.238 \\
\hline 45 & 12 & 4 & 0.3 & 10 & 1.87 & 1.827 & 2.292 & 1.858 & 0.632 & 1.831 & 2.062 \\
\hline 46 & 8 & 4 & 0.3 & 6 & 3.23 & 3.006 & 6.929 & 3.249 & 0.594 & 3.226 & 0.113 \\
\hline 47 & 16 & 4 & 0.2 & 10 & 0.37 & 0.641 & 73.174 & 0.365 & 1.397 & 0.364 & 1.514 \\
\hline 48 & 24 & 3 & 0.2 & 6 & 3.81 & 3.800 & 0.261 & 3.794 & 0.432 & 3.836 & 0.673 \\
\hline 49 & 8 & 4 & 0.2 & 10 & 2.35 & 2.340 & 0.422 & 2.359 & 0.370 & 2.451 & 4.301 \\
\hline 50 & 20 & 5 & 0.1 & 6 & 0.15 & 0.641 & 327.589 & 0.150 & 0.219 & 0.147 & 1.927 \\
\hline 51 & 8 & 3 & 0.2 & 10 & 1.37 & 1.192 & 13.021 & 1.370 & 0.012 & 1.374 & 0.312 \\
\hline 52 & 20 & 4 & 0.1 & 10 & 1.13 & 0.878 & 22.294 & 1.120 & 0.925 & 1.112 & 1.551 \\
\hline 53 & 16 & 3 & 0.1 & 6 & 1.27 & 1.163 & 8.444 & 1.269 & 0.103 & 1.254 & 1.270 \\
\hline 54 & 16 & 3 & 0.2 & 6 & 1.55 & 1.446 & 6.681 & 1.544 & 0.377 & 1.556 & 0.357 \\
\hline 55 & 12 & 5 & 0.1 & 10 & 2.15 & 2.027 & 5.721 & 2.110 & 1.874 & 2.137 & 0.586 \\
\hline 56 & 16 & 5 & 0.1 & 6 & 1.28 & 1.156 & 9.657 & 1.267 & 0.999 & 1.275 & 0.410 \\
\hline 57 & 16 & 3 & 0.3 & 10 & 1.87 & 1.749 & 6.449 & 1.889 & 1.003 & 1.829 & 2.212 \\
\hline 58 & 8 & 5 & 0.1 & 6 & 3.52 & 3.644 & 3.527 & 3.514 & 0.173 & 3.486 & 0.977 \\
\hline 59 & 8 & 3 & 0.3 & 8 & 1.97 & 1.956 & 0.714 & 1.963 & 0.354 & 1.968 & 0.121 \\
\hline 60 & 12 & 4 & 0.2 & 10 & 1.38 & 1.202 & 12.928 & 1.366 & 1.026 & 1.376 & 0.289 \\
\hline 61 & 20 & 5 & 0.3 & 10 & 0.87 & 1.375 & 58.099 & 0.867 & 0.361 & 0.863 & 0.833 \\
\hline 62 & 16 & 3 & 0.1 & 8 & 1.16 & 0.970 & 16.348 & 1.186 & 2.229 & 1.187 & 2.309 \\
\hline 63 & 12 & 5 & 0.2 & 8 & 2.47 & 2.359 & 4.474 & 2.487 & 0.708 & 2.549 & 3.204 \\
\hline 64 & 20 & 3 & 0.1 & 6 & 2.41 & 2.285 & 5.200 & 2.402 & 0.336 & 2.377 & 1.388 \\
\hline 65 & 8 & 4 & 0.3 & 8 & 3.02 & 2.902 & 3.913 & 3.034 & 0.453 & 3.024 & 0.142 \\
\hline 66 & 12 & 4 & 0.1 & 10 & 1.14 & 0.876 & 23.140 & 1.129 & 0.968 & 1.106 & 2.951 \\
\hline 67 & 12 & 5 & 0.2 & 6 & 2.67 & 2.477 & 7.222 & 2.664 & 0.237 & 2.720 & 1.864 \\
\hline 68 & 16 & 5 & 0.2 & 6 & 1.56 & 1.441 & 7.637 & 1.544 & 1.021 & 1.548 & 0.790 \\
\hline 69 & 8 & 3 & 0.1 & 8 & 1.18 & 1.068 & 9.466 & 1.192 & 0.978 & 1.179 & 0.098 \\
\hline 70 & 16 & 5 & 0.2 & 8 & 1.43 & 1.274 & 10.879 & 1.436 & 0.418 & 1.451 & 1.436 \\
\hline 71 & 16 & 4 & 0.3 & 8 & 0.91 & 1.586 & 74.309 & 0.916 & 0.630 & 0.913 & 0.277 \\
\hline 72 & 24 & 5 & 0.1 & 10 & 1.11 & 0.860 & 22.497 & 1.122 & 1.121 & 1.110 & 0.032 \\
\hline 73 & 8 & 5 & 0.1 & 8 & 3.28 & 3.551 & 8.275 & 3.305 & 0.751 & 3.296 & 0.493 \\
\hline 74 & 8 & 3 & 0.3 & 6 & 2.12 & 2.087 & 1.556 & 2.120 & 0.001 & 2.097 & 1.065 \\
\hline 75 & 8 & 5 & 0.3 & 6 & 4.39 & 4.146 & 5.567 & 4.387 & 0.077 & 4.332 & 1.323 \\
\hline 76 & 24 & 5 & 0.3 & 10 & 1.86 & 1.817 & 2.316 & 1.870 & 0.512 & 1.841 & 1.010 \\
\hline 77 & 24 & 4 & 0.1 & 8 & 2.24 & 2.262 & 0.969 & 2.262 & 0.968 & 2.255 & 0.668 \\
\hline 78 & 24 & 5 & 0.1 & 8 & 1.17 & 1.065 & 8.981 & 1.194 & 2.010 & 1.173 & 0.251 \\
\hline 79 & 16 & 4 & 0.3 & 6 & 0.98 & 1.734 & 76.910 & 0.973 & 0.684 & 0.973 & 0.737 \\
\hline 80 & 8 & 4 & 0.1 & 6 & 2.42 & 2.380 & 1.642 & 2.402 & 0.732 & 2.344 & 3.149 \\
\hline 81 & 16 & 4 & 0.2 & 6 & 0.42 & 1.080 & 157.039 & 0.416 & 1.036 & 0.390 & 7.192 \\
\hline 82 & 20 & 3 & 0.2 & 6 & 2.68 & 2.482 & 7.380 & 2.672 & 0.316 & 2.705 & 0.919 \\
\hline 83 & 20 & 5 & 0.3 & 8 & 0.9 & 1.535 & 70.567 & 0.908 & 0.896 & 0.910 & 1.088 \\
\hline 84 & 12 & 3 & 0.2 & 8 & 0.39 & 0.809 & 107.369 & 0.395 & 1.276 & 0.384 & 1.562 \\
\hline 85 & 20 & 3 & 0.3 & 6 & 3.25 & 2.923 & 10.048 & 3.250 & 0.011 & 3.227 & 0.714 \\
\hline 86 & 16 & 3 & 0.2 & 10 & 1.36 & 1.100 & 19.094 & 1.376 & 1.211 & 1.358 & 0.156 \\
\hline
\end{tabular}


Table 5. Cont.

\begin{tabular}{|c|c|c|c|c|c|c|c|c|c|c|c|}
\hline \multirow[b]{2}{*}{ Run } & \multirow[b]{2}{*}{$\begin{array}{c}a_{p} \\
(\mu \mathrm{m})\end{array}$} & \multirow[b]{2}{*}{$\begin{array}{c}R a_{1} \\
(\mu \mathrm{m})\end{array}$} & \multirow[b]{2}{*}{$\underset{(\mathrm{mm})}{f_{b}}$} & \multirow[b]{2}{*}{$\begin{array}{c}D_{b} \\
(\mathrm{~mm})\end{array}$} & \multirow[b]{2}{*}{$\begin{array}{c}R a_{2} \\
\text { Measured } \\
(\mu \mathrm{m})\end{array}$} & \multicolumn{2}{|c|}{ RA } & \multicolumn{2}{|c|}{ ANN } & \multicolumn{2}{|c|}{ SVR } \\
\hline & & & & & & $\begin{array}{c}R a_{2} \\
\text { Predicted } \\
(\mu \mathrm{m})\end{array}$ & $\begin{array}{l}P E \\
(\%)\end{array}$ & $\begin{array}{c}R a_{2} \\
\text { Predicted } \\
(\mu \mathrm{m})\end{array}$ & $\begin{array}{l}P E \\
(\%)\end{array}$ & $\begin{array}{c}R a_{2} \\
\text { Predicted } \\
(\mu \mathrm{m})\end{array}$ & $\begin{array}{l}P E \\
(\%)\end{array}$ \\
\hline 87 & 24 & 3 & 0.1 & 8 & 3.27 & 3.556 & 8.755 & 3.291 & 0.653 & 3.261 & 0.263 \\
\hline 88 & 12 & 4 & 0.2 & 8 & 1.44 & 1.373 & 4.623 & 1.439 & 0.043 & 1.462 & 1.520 \\
\hline 89 & 12 & 4 & 0.3 & 8 & 1.96 & 1.963 & 0.172 & 1.965 & 0.276 & 1.949 & 0.541 \\
\hline 90 & 20 & 4 & 0.3 & 8 & 1.96 & 1.965 & 0.231 & 1.991 & 1.567 & 1.965 & 0.266 \\
\hline 91 & 8 & 5 & 0.3 & 8 & 4.05 & 4.060 & 0.245 & 4.101 & 1.258 & 4.032 & 0.455 \\
\hline 92 & 8 & 5 & 0.1 & 10 & 3.12 & 3.457 & 10.808 & 3.096 & 0.768 & 3.118 & 0.066 \\
\hline 93 & 16 & 4 & 0.3 & 10 & 0.87 & 1.430 & 64.362 & 0.875 & 0.529 & 0.864 & 0.734 \\
\hline 94 & 20 & 5 & 0.1 & 8 & 0.13 & 0.332 & 155.525 & 0.135 & 3.490 & 0.129 & 1.021 \\
\hline 95 & 16 & 4 & 0.1 & 10 & 0.13 & / & / & 0.125 & 3.792 & 0.132 & 1.347 \\
\hline 96 & 16 & 5 & 0.1 & 8 & 1.16 & 0.963 & 16.961 & 1.187 & 2.291 & 1.192 & 2.722 \\
\hline 97 & 8 & 3 & 0.2 & 8 & 1.44 & 1.364 & 5.263 & 1.441 & 0.092 & 1.459 & 1.309 \\
\hline 98 & 24 & 3 & 0.3 & 8 & 4.07 & 4.064 & 0.138 & 3.999 & 1.746 & 4.082 & 0.288 \\
\hline 99 & 12 & 4 & 0.1 & 6 & 1.27 & 1.261 & 0.713 & 1.268 & 0.119 & 1.267 & 0.213 \\
\hline 100 & 12 & 3 & 0.2 & 10 & 0.38 & 0.557 & 46.596 & 0.374 & 1.501 & 0.366 & 3.571 \\
\hline 101 & 12 & 3 & 0.2 & 6 & 0.42 & 1.020 & 142.813 & 0.425 & 1.102 & 0.405 & 3.511 \\
\hline 102 & 16 & 3 & 0.3 & 6 & 2.13 & 2.023 & 5.038 & 2.131 & 0.047 & 2.146 & 0.773 \\
\hline 103 & 20 & 4 & 0.2 & 6 & 1.57 & 1.535 & 2.259 & 1.543 & 1.714 & 1.557 & 0.839 \\
\hline 104 & 20 & 4 & 0.2 & 10 & 1.37 & 1.203 & 12.179 & 1.372 & 0.180 & 1.360 & 0.755 \\
\hline 105 & 24 & 4 & 0.1 & 6 & 2.42 & 2.382 & 1.558 & 2.413 & 0.299 & 2.390 & 1.240 \\
\hline 106 & 8 & 4 & 0.1 & 8 & 2.23 & 2.260 & 1.327 & 2.236 & 0.268 & 2.237 & 0.300 \\
\hline 107 & 20 & 4 & 0.3 & 6 & 2.12 & 2.095 & 1.167 & 2.149 & 1.345 & 2.120 & 0.006 \\
\hline 108 & 8 & 5 & 0.2 & 6 & 3.83 & 3.795 & 0.904 & 3.810 & 0.513 & 3.887 & 1.493 \\
\hline 109 & 24 & 4 & 0.3 & 6 & 3.24 & 3.008 & 7.161 & 3.290 & 1.551 & 3.229 & 0.334 \\
\hline 110 & 8 & 4 & 0.3 & 10 & 2.88 & 2.795 & 2.946 & 2.874 & 0.198 & 2.836 & 1.535 \\
\hline 111 & 8 & 3 & 0.3 & 10 & 1.86 & 1.819 & 2.184 & 1.861 & 0.035 & 1.845 & 0.827 \\
\hline 112 & 20 & 3 & 0.3 & 10 & 2.86 & 2.709 & 5.293 & 2.871 & 0.370 & 2.823 & 1.288 \\
\hline 113 & 12 & 5 & 0.3 & 10 & 2.87 & 2.704 & 5.790 & 2.866 & 0.136 & 2.801 & 2.403 \\
\hline 114 & 8 & 3 & 0.1 & 6 & 1.26 & 1.251 & 0.695 & 1.270 & 0.770 & 1.253 & 0.588 \\
\hline 115 & 20 & 3 & 0.1 & 10 & 2.13 & 2.033 & 4.569 & 2.133 & 0.127 & 2.129 & 0.047 \\
\hline 116 & 24 & 4 & 0.2 & 6 & 2.66 & 2.575 & 3.186 & 2.679 & 0.708 & 2.745 & 3.188 \\
\hline 117 & 24 & 3 & 0.2 & 8 & 3.54 & 3.710 & 4.793 & 3.559 & 0.531 & 3.610 & 1.979 \\
\hline 118 & 24 & 4 & 0.2 & 10 & 2.37 & 2.342 & 1.175 & 2.358 & 0.509 & 2.428 & 2.458 \\
\hline 119 & 24 & 3 & 0.3 & 10 & 3.87 & 3.978 & 2.782 & 3.838 & 0.836 & 3.827 & 1.106 \\
\hline 120 & 16 & 5 & 0.1 & 10 & 1.14 & 0.743 & 34.806 & 1.126 & 1.265 & 1.112 & 2.468 \\
\hline 121 & 20 & 4 & 0.2 & 8 & 1.43 & 1.375 & 3.857 & 1.446 & 1.136 & 1.460 & 2.098 \\
\hline 122 & 16 & 4 & 0.2 & 8 & 0.38 & 0.877 & 130.763 & 0.386 & 1.498 & 0.379 & 0.276 \\
\hline 123 & 24 & 3 & 0.1 & 10 & 3.13 & 3.462 & 10.612 & 3.109 & 0.658 & 3.060 & 2.241 \\
\hline 124 & 24 & 5 & 0.1 & 6 & 1.26 & 1.248 & 0.938 & 1.279 & 1.501 & 1.238 & 1.778 \\
\hline 125 & 20 & 5 & 0.1 & 10 & 0.13 & / & / & 0.124 & 4.887 & 0.121 & 6.739 \\
\hline 126 & 8 & 5 & 0.3 & 10 & 3.86 & 3.973 & 2.930 & 3.860 & 0.008 & 3.698 & 4.200 \\
\hline 127 & 16 & 3 & 0.3 & 8 & 1.99 & 1.889 & 5.074 & 1.991 & 0.075 & 1.982 & 0.396 \\
\hline 128 & 12 & 3 & 0.1 & 10 & 0.13 & / & / & 0.127 & 2.633 & 0.141 & 8.170 \\
\hline 129 & 12 & 3 & 0.3 & 10 & 0.89 & 1.380 & 55.032 & 0.896 & 0.636 & 0.896 & 0.627 \\
\hline 130 & 8 & 5 & 0.2 & 8 & 3.54 & 3.705 & 4.659 & 3.573 & 0.926 & 3.571 & 0.877 \\
\hline 131 & 12 & 4 & 0.1 & 8 & 1.19 & 1.079 & 9.332 & 1.189 & 0.076 & 1.186 & 0.332 \\
\hline 132 & 8 & 4 & 0.2 & 8 & 2.48 & 2.458 & 0.873 & 2.488 & 0.340 & 2.596 & 4.680 \\
\hline 133 & 24 & 5 & 0.2 & 10 & 1.37 & 1.188 & 13.251 & 1.368 & 0.149 & 1.351 & 1.401 \\
\hline 134 & 16 & 5 & 0.3 & 10 & 1.85 & 1.744 & 5.707 & 1.852 & 0.110 & 1.819 & 1.681 \\
\hline 135 & 20 & 3 & 0.1 & 8 & 2.23 & 2.161 & 3.099 & 2.253 & 1.035 & 2.251 & 0.964 \\
\hline
\end{tabular}

\subsection{Confirmation Experiment}

In order to objectively evaluate the efficiency of all three models, additional 48 confirmation experiments were conducted, named confirmation experiment, as explained before. In these experiments, only the values of ball diameters remained unchanged, while the 
other three input parameters (the depth of ball penetration, the initial surface roughness, and burnishing feed) had different values from those used in the training experiment.

During the confirmation experimental research, four processing parameters (input variables) were varied at the following levels:

- $\quad$ The depth of ball penetration $-a_{p}=10,14,18,22(\mu \mathrm{m})$;

- The initial surface roughness- $R a_{1}=3.5,4.5(\mu \mathrm{m})$;

- $\quad$ Burnishing feed- $f_{b}=0.15,0.25(\mathrm{~mm})$;

- Burnishing ball diameter $-D_{b}=6,8,10(\mathrm{~mm})$.

After the confirmation experiments, the measurement and prediction of the final arithmetic mean roughness $\left(R a_{2}\right)$ was performed for the three previously described models (RA, ANN, and SVR). Table 6 shows the obtained results of $R a_{2}$ measurements, $R a_{2}$ predictions, and the obtained percentage errors for the three models.

Table 6. Measured and predicted values of the surface roughness and percentage errors for confirmation experiment.

\begin{tabular}{|c|c|c|c|c|c|c|c|c|c|c|c|}
\hline \multirow[b]{2}{*}{ Run } & \multirow[b]{2}{*}{$\begin{array}{c}a_{p} \\
(\mu \mathrm{m})\end{array}$} & \multirow[b]{2}{*}{$\begin{array}{c}R a_{1} \\
(\mu \mathrm{m})\end{array}$} & \multirow[b]{2}{*}{$\underset{(\mathrm{mm})}{f_{b}}$} & \multirow[b]{2}{*}{$\begin{array}{c}D_{b} \\
(\mathrm{~mm})\end{array}$} & \multirow[b]{2}{*}{$\begin{array}{c}R a_{2} \\
\text { Measured } \\
(\mu \mathrm{m})\end{array}$} & \multicolumn{2}{|c|}{ RA } & \multicolumn{2}{|c|}{ ANN } & \multicolumn{2}{|c|}{ SVR } \\
\hline & & & & & & $\begin{array}{c}R a_{2} \\
\text { Predicted } \\
(\mu \mathrm{m})\end{array}$ & $\begin{array}{l}P E \\
(\%)\end{array}$ & $\begin{array}{c}R a_{2} \\
\text { Predicted } \\
(\mu \mathrm{m})\end{array}$ & $\begin{array}{l}P E \\
(\%)\end{array}$ & $\begin{array}{c}R a_{2} \\
\text { Predicted } \\
(\mu \mathrm{m})\end{array}$ & $\begin{array}{l}P E \\
(\%)\end{array}$ \\
\hline 1 & 10 & 3.5 & 0.15 & 6 & 1.40 & 1.361 & 2.755 & 1.396 & 0.284 & 1.368 & 2.297 \\
\hline 2 & 10 & 3.5 & 0.25 & 6 & 1.81 & 1.793 & 0.940 & 1.814 & 0.229 & 1.785 & 1.394 \\
\hline 3 & 10 & 3.5 & 0.15 & 8 & 1.31 & 1.189 & 9.267 & 1.305 & 0.360 & 1.283 & 2.050 \\
\hline 4 & 10 & 3.5 & 0.25 & 8 & 1.69 & 1.649 & 2.448 & 1.689 & 0.069 & 1.658 & 1.895 \\
\hline 5 & 10 & 3.5 & 0.15 & 10 & 1.25 & 0.999 & 20.072 & 1.239 & 0.887 & 1.210 & 3.191 \\
\hline 6 & 10 & 3.5 & 0.25 & 10 & 1.61 & 1.496 & 7.066 & 1.605 & 0.301 & 1.558 & 3.210 \\
\hline 7 & 14 & 3.5 & 0.15 & 6 & 0.25 & 0.833 & 233.334 & 0.238 & 4.980 & 0.251 & 0.268 \\
\hline 8 & 14 & 3.5 & 0.25 & 6 & 0.67 & 1.370 & 104.405 & 0.701 & 4.562 & 0.649 & 3.203 \\
\hline 9 & 14 & 3.5 & 0.15 & 8 & 0.23 & 0.588 & 155.482 & 0.217 & 5.615 & 0.237 & 3.198 \\
\hline 10 & 14 & 3.5 & 0.25 & 8 & 0.63 & 1.197 & 90.057 & 0.650 & 3.157 & 0.605 & 3.904 \\
\hline 11 & 14 & 3.5 & 0.15 & 10 & 0.22 & 0.248 & 12.603 & 0.210 & 4.676 & 0.227 & 3.202 \\
\hline 12 & 14 & 3.5 & 0.25 & 10 & 0.60 & 1.009 & 68.136 & 0.631 & 5.123 & 0.571 & 4.836 \\
\hline 13 & 18 & 3.5 & 0.15 & 6 & 1.37 & 1.321 & 3.604 & 1.368 & 0.171 & 1.368 & 0.144 \\
\hline 14 & 18 & 3.5 & 0.25 & 6 & 1.81 & 1.759 & 2.845 & 1.805 & 0.249 & 1.791 & 1.044 \\
\hline 15 & 18 & 3.5 & 0.15 & 8 & 1.29 & 1.144 & 11.300 & 1.280 & 0.763 & 1.292 & 0.145 \\
\hline 16 & 18 & 3.5 & 0.25 & 8 & 1.69 & 1.612 & 4.596 & 1.690 & 0.024 & 1.678 & 0.733 \\
\hline 17 & 18 & 3.5 & 0.15 & 10 & 1.23 & 0.950 & 22.791 & 1.210 & 1.597 & 1.215 & 1.201 \\
\hline 18 & 18 & 3.5 & 0.25 & 10 & 1.61 & 1.458 & 9.458 & 1.606 & 0.253 & 1.563 & 2.894 \\
\hline 19 & 22 & 3.5 & 0.15 & 6 & 1.92 & 1.820 & 5.217 & 1.920 & 0.002 & 1.897 & 1.188 \\
\hline 20 & 22 & 3.5 & 0.25 & 6 & 2.33 & 2.193 & 5.871 & 2.334 & 0.156 & 2.313 & 0.724 \\
\hline 21 & 22 & 3.5 & 0.15 & 8 & 1.80 & 1.677 & 6.842 & 1.798 & 0.127 & 1.803 & 0.155 \\
\hline 22 & 22 & 3.5 & 0.25 & 8 & 2.17 & 2.066 & 4.785 & 2.172 & 0.109 & 2.188 & 0.811 \\
\hline 23 & 22 & 3.5 & 0.15 & 10 & 1.70 & 1.526 & 10.228 & 1.701 & 0.054 & 1.724 & 1.400 \\
\hline 24 & 22 & 3.5 & 0.25 & 10 & 2.05 & 1.934 & 5.645 & 2.053 & 0.137 & 2.075 & 1.214 \\
\hline 25 & 10 & 4.5 & 0.15 & 6 & 2.48 & 2.404 & 3.066 & 2.479 & 0.047 & 2.508 & 1.127 \\
\hline 26 & 10 & 4.5 & 0.25 & 6 & 2.93 & 2.726 & 6.959 & 2.925 & 0.177 & 2.920 & 0.344 \\
\hline 27 & 10 & 4.5 & 0.15 & 8 & 2.31 & 2.284 & 1.124 & 2.308 & 0.096 & 2.347 & 1.602 \\
\hline 28 & 10 & 4.5 & 0.25 & 8 & 2.74 & 2.615 & 4.554 & 2.735 & 0.191 & 2.733 & 0.273 \\
\hline 29 & 10 & 4.5 & 0.15 & 10 & 2.18 & 2.160 & 0.907 & 2.175 & 0.242 & 2.211 & 1.436 \\
\hline 30 & 10 & 4.5 & 0.25 & 10 & 2.59 & 2.501 & 3.420 & 2.592 & 0.094 & 2.573 & 0.674 \\
\hline 31 & 14 & 4.5 & 0.15 & 6 & 1.40 & 1.317 & 5.932 & 1.397 & 0.236 & 1.372 & 1.985 \\
\hline 32 & 14 & 4.5 & 0.25 & 6 & 1.81 & 1.755 & 3.016 & 1.809 & 0.033 & 1.782 & 1.525 \\
\hline 33 & 14 & 4.5 & 0.15 & 8 & 1.31 & 1.140 & 12.960 & 1.304 & 0.433 & 1.280 & 2.274 \\
\hline 34 & 14 & 4.5 & 0.25 & 8 & 1.68 & 1.609 & 4.222 & 1.681 & 0.070 & 1.652 & 1.685 \\
\hline 35 & 14 & 4.5 & 0.15 & 10 & 1.25 & 0.945 & 24.385 & 1.239 & 0.901 & 1.207 & 3.431 \\
\hline
\end{tabular}


Table 6. Cont.

\begin{tabular}{|c|c|c|c|c|c|c|c|c|c|c|c|}
\hline \multirow[b]{2}{*}{ Run } & \multirow[b]{2}{*}{$\begin{array}{c}a_{p} \\
(\mu \mathrm{m})\end{array}$} & \multirow[b]{2}{*}{$\begin{array}{c}R a_{1} \\
(\mu \mathrm{m})\end{array}$} & \multirow[b]{2}{*}{$\underset{(\mathrm{mm})}{f_{b}}$} & \multirow[b]{2}{*}{$\begin{array}{c}D_{b} \\
(\mathrm{~mm})\end{array}$} & \multirow[b]{2}{*}{$\begin{array}{c}R a_{2} \\
\text { Measured } \\
(\mu \mathrm{m})\end{array}$} & \multicolumn{2}{|c|}{ RA } & \multicolumn{2}{|c|}{ ANN } & \multicolumn{2}{|c|}{ SVR } \\
\hline & & & & & & $\begin{array}{c}R a_{2} \\
\text { Predicted } \\
(\mu \mathrm{m})\end{array}$ & $\begin{array}{l}P E \\
(\%)\end{array}$ & $\begin{array}{c}R a_{2} \\
\text { Predicted } \\
(\mu \mathrm{m})\end{array}$ & $\begin{array}{l}P E \\
(\%)\end{array}$ & $\begin{array}{c}R a_{2} \\
\text { Predicted } \\
(\mu \mathrm{m})\end{array}$ & $\begin{array}{l}P E \\
(\%)\end{array}$ \\
\hline 36 & 14 & 4.5 & 0.25 & 10 & 1.60 & 1.454 & 9.109 & 1.595 & 0.284 & 1.553 & 2.944 \\
\hline 37 & 18 & 4.5 & 0.15 & 6 & 0.24 & 0.830 & 246.005 & 0.234 & 2.631 & 0.247 & 2.740 \\
\hline 38 & 18 & 4.5 & 0.25 & 6 & 0.67 & 1.367 & 104.081 & 0.699 & 4.292 & 0.641 & 4.344 \\
\hline 39 & 18 & 4.5 & 0.15 & 8 & 0.23 & 0.584 & 153.914 & 0.213 & 7.408 & 0.234 & 1.641 \\
\hline 40 & 18 & 4.5 & 0.25 & 8 & 0.63 & 1.195 & 89.684 & 0.658 & 4.380 & 0.599 & 4.870 \\
\hline 41 & 18 & 4.5 & 0.15 & 10 & 0.21 & 0.242 & 15.064 & 0.198 & 5.529 & 0.223 & 5.981 \\
\hline 42 & 18 & 4.5 & 0.25 & 10 & 0.60 & 1.006 & 67.701 & 0.628 & 4.701 & 0.566 & 5.640 \\
\hline 43 & 22 & 4.5 & 0.15 & 6 & 0.80 & 0.985 & 23.175 & 0.816 & 2.006 & 0.784 & 2.028 \\
\hline 44 & 22 & 4.5 & 0.25 & 6 & 1.22 & 1.486 & 21.763 & 1.231 & 0.911 & 1.201 & 1.534 \\
\hline 45 & 22 & 4.5 & 0.15 & 8 & 0.73 & 0.769 & 5.342 & 0.746 & 2.248 & 0.763 & 4.559 \\
\hline 46 & 22 & 4.5 & 0.25 & 8 & 1.13 & 1.322 & 17.025 & 1.120 & 0.927 & 1.146 & 1.433 \\
\hline 47 & 22 & 4.5 & 0.15 & 10 & 0.66 & 0.507 & 23.224 & 0.674 & 2.093 & 0.636 & 3.585 \\
\hline 48 & 22 & 4.5 & 0.25 & 10 & 1.03 & 1.146 & 11.277 & 1.041 & 1.039 & 1.050 & 1.907 \\
\hline
\end{tabular}

\section{Discussion}

Descriptive parameters of the measured values of surface roughness after ball burnishing during the training and confirmation experiments are shown in Table 7. The values of the surface roughness range from $0.13 \mu \mathrm{m}$ to $4.39 \mu \mathrm{m}$. This points to two very important facts. First, a minimum surface roughness value of $0.13 \mu \mathrm{m}$ indicates that the extremely high quality of the treated surface can be obtained by this procedure. Second, the ratio of maximum and minimum values $\left(R a_{\max } / R a_{\min }\right)$ of 33.77 is extremely high. This indicates that with a suitable combination of process parameters, $R a$ can be significantly affected. In other words, a suitable choice of input parameters of the process can achieve the required roughness in a very wide range. This is important from the point of view of practical application, considering that it is not necessary to insist on the minimum but on the required surface roughness. The predicted values of $R a$ have the same trend as the measured values. The $R a$ values obtained by the training and confirmation experiments have close values for the RA, ANN, and SVR models. Differences between values are acceptable and occur as a consequence of the fact that the confirmation was performed on the input parameters on which no training was performed, i.e., on "unknown" input variables. Moreover, the $M P E$ for the ANN and SVR models is lower for confirmation experiments than for training experiments, while for the RA model, it is negligibly higher. This confirmed the correct choice of training parameters and the correctly performed training process for all models.

Table 7. Descriptive parameters of the surface roughness $R a_{2}$ measured.

\begin{tabular}{ccc}
\hline \multirow{2}{*}{ Parameter } & \multicolumn{2}{c}{$\boldsymbol{R} \boldsymbol{a}_{\mathbf{2}}$ Measured $(\boldsymbol{\mu m})$} \\
\cline { 2 - 3 } & Training Experiments & Confirmation Experiments \\
\hline Min & 0.13 & 0.21 \\
Max & 4.39 & 2.93 \\
Mean & 1.90 & 1.36 \\
St. dev. & 1.06 & 0.73 \\
Ratio & 33.77 & 13.95 \\
\hline
\end{tabular}

In most experiments (Tables 5 and 6), the surface roughness after the ball burnishing process is lower than the initial one $\left(R a_{2}<R a_{1}\right)$, which was the goal. However, in several experiments, it can be observed that the surface roughness obtained after the ball burnishing process was higher than the initial surface roughness, i.e., $R a_{2}>R a_{1}$. This is a consequence of inadequate process parameters. These are also cases that represent the full expediency of the modeling process because the knowledge and experience of the operator are minimized 
if the process is well modeled, and inadequate process parameters that can lead to scrap are avoided.

Based on the results of experiments, the following can generally be stated:

- The depths of ball penetration close to the maximum profile height before processing generate the lowest surface roughness. For depth values greater and smaller than this one, the surface roughness increases;

- As the burnishing feed decreases, the surface roughness reduces;

- As the ball diameter increases, the surface roughness reduces.

Figure 3 shows an archlike dependence of the surface roughness obtained after ball burnishing $\left(R a_{2}\right)$ in relation to the initial surface roughness $\left(R a_{1}\right)$ and the depth of ball penetration $\left(a_{p}\right)$. For depths of ball penetration $\left(a_{p}\right)$ lower than the initial value of the profile height, when the ball reaches and "touches" the treated surface under the effect of high contact pressures, the peaks begin to flow and fill the valleys in the roughness profile and reduce surface roughness. This happens up to a certain depth of ball penetration $\left(a_{p}\right)$, approximately when $a_{p} \approx R p$. For these values, the lowest surface roughness was achieved after processing. With a further increase in the depth of ball penetration $\left(a_{p}\right)$, the surface roughness $\left(R a_{2}\right)$ worsens. Larger depths of ball penetration $\left(a_{p}\right)$ cause the emergence of larger valleys, which results in higher roughness $\left(R a_{2}\right)$, i.e., a reduction in the quality of the treated surface. Larger depths of ball penetration $\left(a_{p}\right)$ also induce greater forces that can damage the surface and create surface cracks. At greater depths of ball penetration $\left(a_{p}\right)$, the depth of the valleys enlarges, which results in a large amount of plastic deformation that causes deeper traces of penetration. As a result, the surface roughness worsens $\left(R a_{2}\right)$, and cracks can occur, which further damages the surface topography. The effect of the deterioration of surface roughness after a certain depth of ball penetration $\left(a_{p}\right)$ can be attributed to the greater hardening of the superficial workpiece layer due to compression. Furthermore, there may be a superficial peeling on the workpiece. With the reduction in burnishing feed $\left(f_{b}\right)$ and with the unchanged other process parameters, the roughness of the treated surface $\left(R a_{2}\right)$ reduces. In all experimental studies, the surface roughness $\left(R a_{2}\right)$ increased with increasing burnishing feed $\left(f_{b}\right)$, while the increased trend remains mild. The burnishing feed $\left(f_{b}\right)$ values were selected so as not to negatively affect the surface that was processed during the earlier tool movement. If two consecutive movements of the ball are close to each other, the material of the workpiece that has already filled the valleys could begin to overflow laterally (perpendicular to the direction of the movement) and thus worsen the roughness $\left(R a_{2}\right)$ of the pre-treated surface on which the peaks have already filled valleys. This negative phenomenon, in the context of the movement, was avoided in this research. A larger ball diameter $\left(D_{b}\right)$, under the unchanged other processing conditions, reduces the surface roughness $\left(R a_{2}\right)$. This can be explained by the very nature of the process, i.e., the contact that takes place between the ball and the treated surface. With larger ball diameters $\left(D_{b}\right)$, the contact area between the tool and the treated surface is larger, which reduces roughness $\left(R a_{2}\right)$.

Descriptive parameters for $P E$ obtained by modeling via RA, ANN, and SVR are shown in Tables 8 and 9. Figure 9 shows the $P E$ for all conducted experiments. The ANN and SVR models predicted the obtained roughness for both experimental data and the "unknown" data very successfully during confirmation experiments, while prediction using the RA model indicated significantly lower accuracy, especially in cases when surface roughness values were very low. Based on the obtained data, identical trends can be observed for both the training experiment and the confirmation experiments. The lowest minimum and mean $P E$ is provided by ANN, while the lowest maximum PE is suggested by SVR. 
Table 8. Descriptive parameters of percentage errors for the training experiments.

\begin{tabular}{|c|c|c|c|c|}
\hline \multirow{2}{*}{ Surface Roughness } & \multirow{2}{*}{ Parameter } & \multicolumn{3}{|c|}{ Main Experiment } \\
\hline & & RA & ANN & SVR \\
\hline \multirow{5}{*}{$R a_{2}<1 \mu \mathrm{m}$} & No. & & 27 & \\
\hline & Min & 46.596 & 0.112 & 0.276 \\
\hline & Max & 418.053 & 8.584 & 8.170 \\
\hline & Mean & 134.513 & 2.293 & 2.888 \\
\hline & St. dev. & 102.671 & 2.482 & 2.351 \\
\hline \multirow{5}{*}{$1 \mu \mathrm{m}<R a_{2}<2 \mu \mathrm{m}$} & No. & & 48 & \\
\hline & Min & 0.172 & 0.012 & 0.032 \\
\hline & Max & 34.806 & 2.291 & 3.804 \\
\hline & Mean & 9.080 & 0.777 & 1.086 \\
\hline & St. dev. & 8.744 & 0.653 & 0.924 \\
\hline \multirow{5}{*}{$2 \mu \mathrm{m}<R a_{2}<3 \mu \mathrm{m}$} & No. & & 34 & \\
\hline & Min & 0.422 & 0.001 & 0.006 \\
\hline & Max & 7.380 & 1.874 & 4.680 \\
\hline & Mean & 3.413 & 0.504 & 1.783 \\
\hline & St. dev. & 2.063 & 0.410 & 1.269 \\
\hline \multirow{5}{*}{$3 \mu \mathrm{m}<R a_{2}<4 \mu \mathrm{m}$} & No. & & 22 & \\
\hline & Min & 0.261 & 0.008 & 0.066 \\
\hline & Max & 10.808 & 1.551 & 4.200 \\
\hline & Mean & 6.026 & 0.478 & 0.983 \\
\hline & St. dev. & 3.068 & 0.361 & 0.952 \\
\hline \multirow{5}{*}{$4 \mu \mathrm{m}<R a_{2}<5 \mu \mathrm{m}$} & No. & & 4 & \\
\hline & Min & 0.138 & 0.077 & 0.288 \\
\hline & Max & 5.567 & 4.301 & 1.323 \\
\hline & Mean & 2.800 & 1.846 & 0.633 \\
\hline & St. dev. & 3.015 & 1.781 & 0.467 \\
\hline \multirow{5}{*}{ All experiments } & No. & & 135 & \\
\hline & Min & 0.138 & 0.001 & 0.006 \\
\hline & Max & 418.053 & 8.584 & 8.170 \\
\hline & Mean & 29.727 & 0.995 & 1.592 \\
\hline & St. dev. & 65.917 & 1.400 & 1.563 \\
\hline
\end{tabular}

Table 9. Descriptive parameters of percentage errors for the confirmation experiments.

\begin{tabular}{|c|c|c|c|c|}
\hline \multirow{2}{*}{ Surface Roughness } & \multirow{2}{*}{ Parameter } & \multicolumn{3}{|c|}{ Confirmation Experiment } \\
\hline & & RA & ANN & SVR \\
\hline \multirow{5}{*}{$R a_{2}<1 \mu \mathrm{m}$} & No. & & 15 & \\
\hline & Min & 5.342 & 2.006 & 0.268 \\
\hline & Max & 246.005 & 7.408 & 5.981 \\
\hline & Mean & 92.814 & 4.227 & 3.600 \\
\hline & St. dev. & 76.632 & 1.530 & 1.539 \\
\hline \multirow{5}{*}{$1 \mu \mathrm{m}<R a_{2}<2 \mu \mathrm{m}$} & No. & & 24 & \\
\hline & Min & 0.940 & 0.002 & 0.144 \\
\hline & Max & 24.385 & 1.597 & 3.431 \\
\hline & Mean & 9.547 & 0.425 & 1.736 \\
\hline & St. dev. & 6.983 & 0.418 & 0.952 \\
\hline \multirow{5}{*}{$2 \mu \mathrm{m}<R a_{2}<3 \mu \mathrm{m}$} & No. & & 9 & \\
\hline & Min & 0.907 & 0.047 & 0.273 \\
\hline & Max & 6.959 & 0.242 & 1.602 \\
\hline & Mean & 4.037 & 0.139 & 0.912 \\
\hline & St. dev. & 2.089 & 0.060 & 0.464 \\
\hline \multirow{5}{*}{ All experiments } & No. & & 48 & \\
\hline & Min & 0.907 & 0.002 & 0.144 \\
\hline & Max & 246.005 & 7.408 & 5.981 \\
\hline & Mean & 34.534 & 1.559 & 2.164 \\
\hline & St. dev. & 57.921 & 2.024 & 1.496 \\
\hline
\end{tabular}



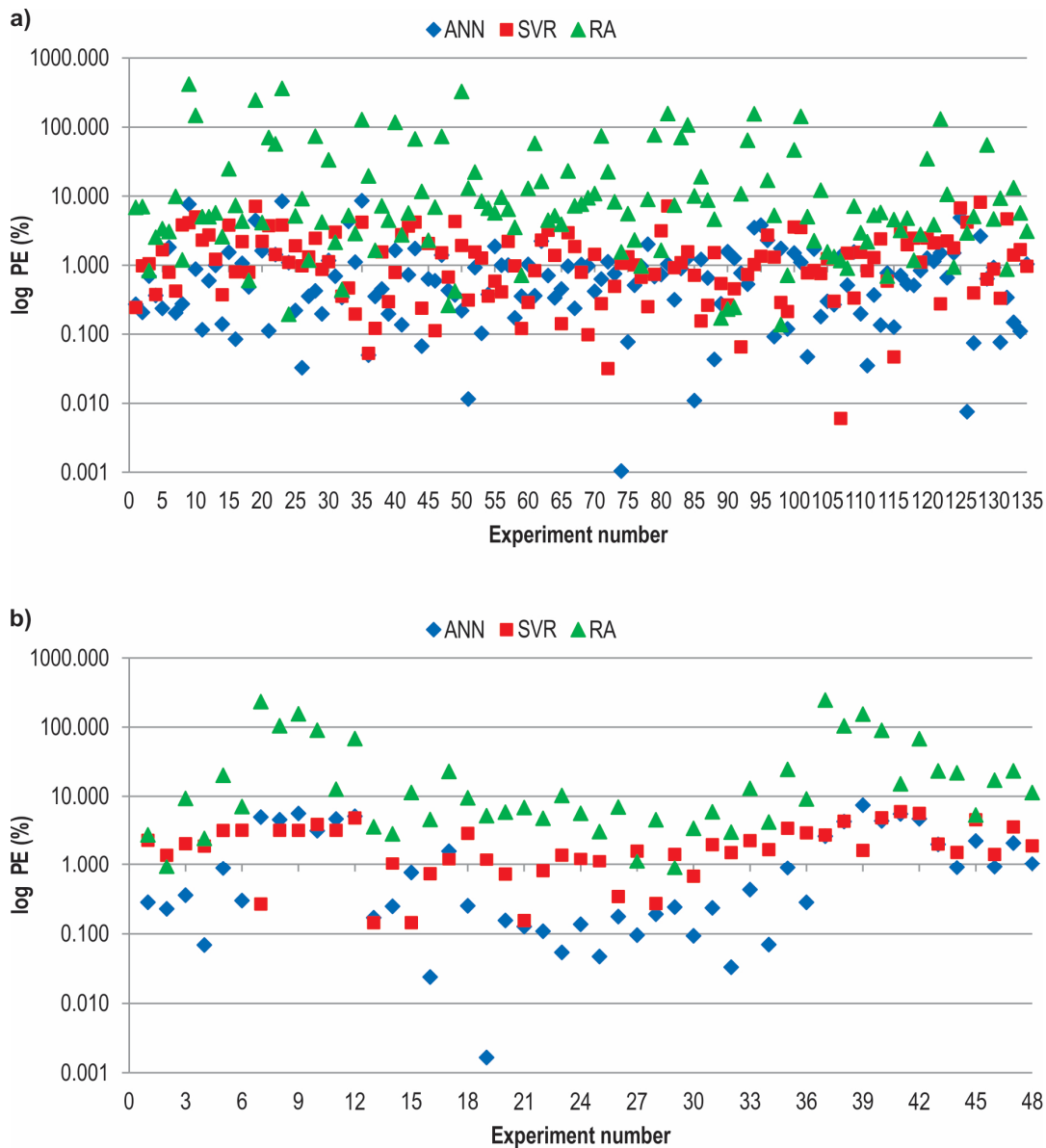

Figure 9. Percentage errors (a) training experiments; (b) confirmation experiments.

Out of a total of 183 experiments conducted, percentage errors PE greater than 5\% occur only for eight predictions via ANN and six predictions via SVR. It should be noted that in these, from the point of view of prediction, the most unfavorable cases, the absolute error, i.e., the difference between the realized and the predicted value of $R a$ is in the range $0.01-0.03 \mu \mathrm{m}$, which is an acceptable deviation from a practical point of view. In all other cases, the errors obtained via ANN and SVR are significantly lower. Therefore, ANN and SVR models can be implemented in the actual industrial conditions, while the RA model can be successfully applied when it is not necessary to obtain extremely low surface roughness.

\section{Conclusions}

This paper discusses the application of the burnishing process on a workpiece made of AISI 4130 alloy steel with a high-stiffness tool and a ceramic ball. Different values of process input parameters were applied to assess their effect on the surface roughness of the workpiece after processing. Three methods were applied in the process modeling, RA, ANN, and SVR, respectively.

Based on experimental and modeling investigations, it is possible to draw several conclusions:

- The obtained experimental results of surface roughness indicate the values of surface roughness range from $0.13 \mu \mathrm{m}$ to $4.39 \mu \mathrm{m}$, which means that it is possible to obtain very low values of surface roughness, below $1 \mu \mathrm{m}$. The minimum value of surface roughness after ball burnishing was $0.13 \mu \mathrm{m}$, which relates to the N3 International Organization for Standardization (ISO) grade number. This is a very high quality of the treated surface;

- The influence of input variables on surface roughness after ball burnishing is different. The depths of ball penetration close to the maximum profile height before processing 
generate the lowest surface roughness. For depth values greater and smaller than this one, the surface roughness increases. Moreover, the surface roughness decreases with decreasing burnishing feed and with increasing ball diameter;

- The quality of RA, ANN, and SVM models was assessed based on the results of the training and confirmation experiments. The evaluation of the model was performed based on PEs. For a complete series of conducted experiments, the minimum and mean PES are lower for the ANN model, but the maximum PE is lower for the SVR model. Bigger errors, but without a significant effect on applicability in practice, are obtained for values of $R a<1 \mu \mathrm{m}$. For surface roughness values $R a \geq 1 \mu \mathrm{m}$, these errors are negligible from a practical point of view since the majority of $P E$ is lower than $1 \%$; - $\quad$ The obtained PES for ANN and SVR models are considered acceptable for practical application. ANN and SVR models have successfully predicted surface roughness, so they can be successfully implemented in the industry when planning the production process.

The main limitation of the applied methodology is that the process was modeled for certain experimental conditions in terms of defined tools, workpieces, and equipment. However, the applied approach is sufficiently general and universal so that it can be easily applied and implemented for other conditions of the ball burnishing process.

Future research will focus on investigating the ball burnishing process with other modeling methods. Furthermore, the aim is to cover a larger number of input and output processing parameters, as well as to perform multi-criteria optimization of the ball burnishing process.

Author Contributions: Conceptualization, Z.K., M.P., B.T. and G.S.; methodology, Z.K., D.V., K.S. and G.S.; software, Z.K. and K.S.; validation, D.V., M.P. and B.T.; formal analysis, K.S. and T.S.; investigation, M.P., T.S. and G.S.; resources, D.V. and B.T.; data curation, Z.K. and K.S.; writingoriginal draft preparation, Z.K., D.V., K.S. and M.P.; writing-review and editing, T.S., B.T. and G.S.; visualization, T.S.; supervision, G.S. All authors have read and agreed to the published version of the manuscript.

Funding: This research was funded by the University of Slavonski Brod, Mechanical Engineering Faculty in Slavonski Brod, Republic of Croatia, grant number SV001 and by the Ministry of Education, Science and Technological Development of Republic of Serbia, grant number 451-03$68 / 2021-14 / 200156$

Institutional Review Board Statement: Not applicable.

Informed Consent Statement: Not applicable.

Data Availability Statement: Not applicable.

Conflicts of Interest: The authors declare no conflict of interest.

\section{References}

1. Maximov, J.T.; Duncheva, G.V.; Anchev, A.P.; Ichkova, M.D. Slide burnishing-Review and prospects. Int. J. Adv. Manuf. Technol. 2019, 104, 785-801. [CrossRef]

2. Tadic, B.; Randjelovic, S.; Todorovic, P.; Zivkovic, J.; Kocovic, V.; Budak, I.; Vukelic, D. Using a high-stiffness burnishing tool for increased dimensional and geometrical accuracies of openings. Precis. Eng. 2016, 43, 335-344. [CrossRef]

3. Travieso-Rodríguez, J.A.; Dessein, G.; González-Rojas, H.A. Improving the surface finish of concave and convex surfaces using a ball burnishing process. Mater. Manuf. Process. 2011, 26, 1494-1502. [CrossRef]

4. Saldana-Robles, A.; Plascencia-Mora, H.; Aguilera-Gómez, E.; Saldana-Robles, A.; Marquez-Herrera, A.; Diosdado-De la Peña, J.A. Influence of ball-burnishing on roughness, hardness and corrosion resistance of AISI 1045 steel. Surf. Coat. Technol. 2018, 339, 191-198. [CrossRef]

5. Vukelic, D.; Tadic, B.; Dzunic, D.; Kocovic, V.; Brzakovic, L.; Zivkovic, M.; Simunovic, G. Analysis of ball-burnishing impact on barrier properties of wood workpieces. Int. J. Adv. Manuf. Technol. 2017, 92, 129-138. [CrossRef]

6. Shreehah, T.A.A. Developing and investigating of elastic ball burnishing tool. Int. J. Adv. Manuf. Technol. 2008, 36, 270-279. [CrossRef]

7. Gharbi, F.; Sghaier, S.; Al-Fadhalah, K.J.; Benameur, T. Effect of ball burnishing process on the surface quality and microstructure properties of AISI 1010 steel plates. J. Mater. Eng. Perform. 2011, 20, 903-910. [CrossRef] 
8. Hamadache, H.; Zemouri, Z.; Laouar, L.; Dominiak, S. Improvement of surface conditions of 36 Cr Ni Mo 6 steel by ball burnishing process. J. Mech. Sci. Technol. 2014, 28, 1491-1498. [CrossRef]

9. Banh, Q.N.; Shiou, F.J. Determination of Optimal Small Ball-Burnishing Parameters for Both Surface Roughness and Superficial Hardness Improvement of STAVAX. Arab. J. Sci. Eng. 2016, 41, 639-652. [CrossRef]

10. Shiou, F.J.; Banh, Q.N. Development of an innovative small ball-burnishing tool embedded with a load cell. Int. J. Adv. Manuf. Technol. 2016, 87, 31-41. [CrossRef]

11. Garcia-Granada, A.A.; Gomez-Gras, G.; Jerez-Mesa, R.; Travieso-Rodriguez, J.A.; Reyes, G. Ball-burnishing effect on deep residual stress on AISI 1038 and AA2017-T4. Mater. Manuf. Process. 2017, 32, 1279-1289. [CrossRef]

12. Boozarpoor, M.; Elyasi, M.; Hosseinzadeh, M. An investigation of the surface quality of burnished AISI 4340 steel. Proc. Inst. Mech. Eng. E J. Process. Mech. Eng. 2018, 232, 299-313. [CrossRef]

13. Bounouara, A.; Hamadache, H.; Amirat, A. Investigation on the effect of ball burnishing on fracture toughness in spiral API X70 pipeline steel. Int. J. Adv. Manuf. Technol. 2018, 94, 4543-4551. [CrossRef]

14. El-Tayeb, N.S.M.; Low, K.O.; Brevern, P.V. Enhancement of surface quality and tribological properties using ball burnishing process. Mach. Sci. Technol. 2008, 12, 234-248. [CrossRef]

15. El-Axir, M.H. An investigation into the ball burnishing of aluminium alloy 6061-T6. Proc. Inst. Mech. Eng. B J. Eng. Manuf. 2007, 221, 1733-1742. [CrossRef]

16. Chomienne, V.; Valiorgue, F.; Rech, J.; Verdu, C. Influence of ball burnishing on residual stress profile of a 15-5PH stainless steel. CIRP J. Manuf. Sci. Technol. 2016, 13, 90-96. [CrossRef]

17. Cao, C.; Zhu, J.; Tanaka, T.; Shiou, F.J.; Sawada, S.; Yoshioka, H. Ball burnishing of Mg alloy using a newly developed burnishing tool with on-machine force control. Int. J. Autom. Technol. 2019, 13, 619-630. [CrossRef]

18. Vukelic, D.; Miljanic, D.; Randjelovic, S.; Budak, I.; Dzunic, D.; Eric, M.; Pantic, M. A burnishing process based on the optimal depth of workpiece penetration. Mater. Tehnol. 2013, 47, 43-51.

19. Tadic, B.; Todorovic, P.; Luzanin, O.; Miljanic, D.; Jeremic, B.; Bogdanovic, B.; Vukelic, D. Using specially designed high-stiffness burnishing tool to achieve high-quality surface finish. Int. J. Adv. Manuf. Technol. 2013, 67, 601-611. [CrossRef]

20. Randjelovic, S.; Tadic, B.; Todorovic, P.M.; Vukelic, D.; Miloradovic, D.; Radenkovic, M.; Tsiafis, C. Modelling of the ball burnishing process with a high-stiffness tool. Int. J. Adv. Manuf. Technol. 2015, 81, 1509-1518. [CrossRef]

21. Travieso-Rodriguez, J.A.; Gomez-Gras, G.; Dessein, G.; Carrillo, F.; Alexis, J.; Jorba-Peiro, J.; Aubazac, N. Effects of a ballburnishing process assisted by vibrations in G10380 steel specimens. Int. J. Adv. Manuf. Technol. 2015, 81, 1757-1765. [CrossRef]

22. Travieso-Rodriguez, J.A.; Gras, G.G.; Peiro, J.J.; Carrillo, F.; Dessein, G.; Alexis, J.; Rojas, H.G. Experimental study on the mechanical effects of the vibration-assisted ball-burnishing process. Mater. Manuf. Process. 2015, 30, 1490-1497. [CrossRef]

23. Gomez-Gras, G.; Travieso-Rodriguez, J.A.; Gonzalez-Rojas, H.A.; Napoles-Alberro, A.; Carrillo, F.J.; Dessein, G. Study of a ball-burnishing vibration-assisted process. Proc. Inst. Mech. Eng. B J. Eng. Manuf. 2015, 229, 172-177. [CrossRef]

24. Gomez-Gras, G.; Travieso-Rodriguez, J.A.; Jerez-Mesa, R.; Lluma-Fuentes, J.; Gomis de la Calle, B. Experimental study of lateral pass width in conventional and vibrations-assisted ball burnishing. Int. J. Adv. Manuf. Technol. 2016, 87, 363-371. [CrossRef]

25. Teimouri, R.; Amini, S.; Bami, A.B. Evaluation of optimized surface properties and residual stress in ultrasonic assisted ball burnishing of AA6061-T6. Measurement 2018, 116, 129-139. [CrossRef]

26. Teimouri, R.; Liu, Z. An analytical prediction model for residual stress distribution and plastic deformation depth in ultrasonicassisted single ball burnishing process. Int. J. Adv. Manuf. Technol. 2020, 111, 127-147. [CrossRef]

27. Lluma, J.; Gomez-Gras, G.; Jerez-Mesa, R.; Rue-Mascarell, J.; Travieso-Rodriguez, J.A. Mechanical strengthening in s235jr steel sheets through vibration-assisted ball burnishing. Metals 2020, 10, 1010. [CrossRef]

28. Jerez-Mesa, R.; Landon, Y.; Travieso-Rodriguez, J.A.; Dessein, G.; Lluma-Fuentes, J.; Wagner, V. Topological surface integrity modification of AISI 1038 alloy after vibration-assisted ball burnishing. Surf. Coat. Technol. 2018, 349, 364-377. [CrossRef]

29. Jerez-Mesa, R.; Travieso-Rodriguez, J.A.; Gomez-Gras, G.; Lluma-Fuentes, J. Development, characterization and test of an ultrasonic vibration-assisted ball burnishing tool. J. Mater. Process. Technol. 2018, 257, 203-212. [CrossRef]

30. Jerez-Mesa, R.; Plana-García, V.; Llumà, J.; Travieso-Rodriguez, J.A. Enhancing surface topology of udimet ${ }^{\circledR} 720$ superalloy through ultrasonic vibration-assisted ball burnishing. Metals 2020, 10, 915. [CrossRef]

31. Jerez-Mesa, R.; Fargas, G.; Roa, J.J.; Llumà, J.; Travieso-Rodriguez, J.A. Superficial effects of ball burnishing on trip steel AISI 301ln sheets. Metals 2021, 11, 82. [CrossRef]

32. Ituarte, I.F.; Salmi, M.; Papula, S.; Huuki, J.; Hemming, B.; Coatanea, E.; Nurmi, S.; Virkkunen, I. Surface modification of additively manufactured $18 \%$ nickel maraging steel by ultrasonic vibration-assisted ball burnishing. J. Manuf. Sci. Eng. Trans. ASME 2020 142, 4046903. [CrossRef]

33. Kovacs, Z.F.; Viharos, Z.J.; Kodacsy, J. Determination of the working gap and optimal machining parameters for magnetic assisted ball burnishing. Measurement 2018, 118, 172-180. [CrossRef]

34. Kovacs, Z.F.; Viharos, Z.J.; Kodacsy, J. Surface flatness and roughness evolution after magnetic assisted ball burnishing of magnetizable and non-magnetizable materials. Measurement 2020, 158, 107750. [CrossRef]

35. Livatyali, H.; Has, E.; Turkoz, M. Prediction of residual stresses in ball burnishing TI6AL4V thin sheets. Int. J. Adv. Manuf. Technol. 2020, 110, 1083-1093. [CrossRef]

36. Sayahi, M.; Sghaier, S.; Belhadjsalah, H. Finite element analysis of ball burnishing process: Comparisons between numerical results and experiments. Int. J. Adv. Manuf. Technol. 2013, 67, 1665-1673. [CrossRef] 
37. Saldana-Robles, A.; Aguilera-Gómez, E.; Plascencia-Mora, H.; Ledesma-Orozco, E.R.; Saldana-Robles, N.; Reveles-Arredondo, J.F. Three-dimensional modeling of surface roughness for burnishing process. DYNA 2015, 90, 423-432. [CrossRef]

38. Mohammadi, F.; Sedaghati, R.; Bonakdar, A. A Finite element analysis and design optimization of low plasticity burnishing process. Int. J. Adv. Manuf. Technol. 2014, 70, 1337-1354. [CrossRef]

39. Charfeddine, Y.; Youssef, S.; Sghaier, S.; Sghaier, J.; Hamdi, H. Study of the simultaneous Grinding/Ball-burnishing of AISI 4140 based on finite element simulations and experiments. Int. J. Mech. Sci. 2021, 192, 106097. [CrossRef]

40. Borysenko, D.; Welzel, F.; Karpuschewski, B.; Kundrak, J.; Voropai, V. Simulation of the burnishing process on real surface structures. Precis. Eng. 2021, 68, 166-173. [CrossRef]

41. Uddin, M.S.; Hall, C.; Hooper, R.; Charrault, E.; Murphy, P.; Santos, V. Finite element analysis of surface integrity in deep ball-burnishing of a biodegradable AZ31B Mg alloy. Metals 2018, 8, 136. [CrossRef]

42. Amini, C.; Jerez-Mesa, R.; Travieso-Rodriguez, J.A.; Llumà, J.; Estevez-Urra, A. Finite element analysis of ball burnishing on ball-end milled surfaces considering their original topology and residual stress. Metals 2020, 10, 638. [CrossRef]

43. Sagbas, A.; Kahraman, F. Determination of optimal ball burnishing parameters for surface hardness. Mater. Tehnol. 2009, 43, 271-274.

44. El-Taweel, T.A.; El-Axir, M.H. Analysis and optimization of the ball burnishing process through the Taguchi technique. Int. J. Adv. Manuf. Technol. 2009, 41, 301-310. [CrossRef]

45. Esme, U. Use of grey based Taguchi method in ball burnishing process for the optimization of surface roughness and microhardness of AA 7075 aluminum alloy. Mater. Tehnol. 2010, 44, 129-135.

46. Babu, P.R.; Ankamma, K.; Prasad, T.S.; Raju, A.V.S.; Prasad, N.E. Optimization of burnishing parameters and determination of select surface characteristics in engineering materials. Sadhana-Acad. Proc. Eng. Sci. 2012, 37, 503-520. [CrossRef]

47. Revankar, G.D.; Shetty, R.; Rao, S.S.; Gaitonde, V.N. Selection of optimal process parameters in ball burnishing of titanium alloy. Mach. Sci. Technol. 2014, 18, 464-483. [CrossRef]

48. Ramesh, D.R.; Prasad, A.M.K.; Kumar, A.C.S. Analysis of ball and roller burnishing by optimizing the process parameters for surface roughness indices using grey based Taguchi method. Int. J. Appl. Eng. Res. 2014, 9, 7191-7200.

49. Cagan, S.C.; Aci, M.; Buldum, B.B.; Aci, C. Artificial neural networks in mechanical surface enhancement technique for the prediction of surface roughness and microhardness of magnesium alloy. Bull. Pol. Acad. Sci. Technol. Sci. 2019, 67, 729-739. [CrossRef]

50. Jawahar, M.; Suresh kumar, J.; Srikiran, M.; Ismail, S. Experimental Investigation of Ball Burnishing Process Parameters Optimization for Al 5083 Using Taguchi Method. In Lecture Notes in Mechanical Engineering; Recent Trends in Mechanical Engineering; Narasimham, G., Babu, A., Reddy, S., Dhanasekaran, R., Eds.; Springer: Singapore, 2020; pp. 189-204. [CrossRef]

51. Stalin John, M.R.; Vinayagam, B.K. Optimization of Ball Burnishing Process on Tool Steel (T215Cr12) in CNC Machining Centre Using Response Surface Methodology. Arab. J. Sci. Eng. 2011, 36, 1407-1422. [CrossRef]

52. Sagbas, A. Analysis and optimization of surface roughness in the ball burnishing process using response surface methodology and desirabilty function. Adv. Eng. Softw. 2011, 42, 992-998. [CrossRef]

53. Kahraman, F. Application of the response surface methodology in the ball burnishing process for the prediction and analysis of surface hardness of the aluminum alloy AA 7075. Mater. Test. 2015, 57, 311-315. [CrossRef]

54. Amdouni, H.; Bouzaiene, H.; Montagne, A.; Nasri, M.; Iost, A. Modeling and optimization of a ball-burnished aluminum alloy flat surface with a crossed strategy based on response surface methodology. Int. J. Adv. Manuf. Technol. 2017, 88, 801-814. [CrossRef]

55. Nguyen, T.T.; Le, C.H. Optimization of compressed air assisted-turning-burnishing process for improving machining quality, energy reduction and cost-effectiveness. Proc. Inst. Mech. Eng. B J. Eng. Manuf. 2021, 235, 1179-1196. [CrossRef]

56. Nguyen, T.T.; Cao, L.H. Optimization of the Burnishing Process for Energy Responses and Surface Properties. Int. J. Precis. Eng. Manuf. 2020, 21, 1143-1152. [CrossRef]

57. Basak, H.; Goktas, H.H. Burnishing process on al-alloy and optimization of surface roughness and surface hardness by fuzzy logic. Mater. Des. 2009, 30, 1275-1281. [CrossRef]

58. Al-Saeedi, S.; Sarhan, A.A.D.; Bushroa, A.R. Investigating the Surface Tribology of Roller-Burnished Polymer Using the Fuzzy Rule-Based Approach. Tribol. Trans. 2015, 58, 240-246. [CrossRef]

59. Ibrahim, A.A.; Abd Rabbo, S.M.; El-Axir, M.H.; Ebied, A.A. Center rest balls burnishing parameters adaptation of steel components using fuzzy logic. J. Mater. Process. Technol. 2009, 209, 2428-2435. [CrossRef]

60. Esme, U.; Kulekci, M.K.; Ustun, D.; Kahraman, F.; Kazancoglu, Y. Grey-based fuzzy algorithm for the optimization of the ball burnishing process. Mater. Test. 2015, 57, 666-673. [CrossRef]

61. Esme, U.; Sagbas, A.; Kahraman, F.; Kulekci, M.K. Use of artificial neural networks in ball burnishing process for the prediction of surface roughness of AA 7075 aluminum alloy. Mater. Tehnol. 2008, 42, 215-219.

62. Esme, U.; Kulekci, M.K.; Ozgun, S.; Kazancoglu, Y. Predictive modelling of ball burnishing process using regression analysis and neural network. Mater. Test. 2013, 55, 187-192. [CrossRef]

63. Basak, H.; Ozkan, M.T.; Toktas, I. Experimental research and ANN modeling on the impact of the ball burnishing process on the mechanical properties of 5083 Al-Mg material. Kov. Mater. 2019, 57, 61-74. [CrossRef]

64. Basak, H.; Sonmez, F. Examination of the effects of burnishing apparatus on surface roughness and hardness in burnishing process. Indian J. Eng. Mater. Sci. 2017, 24, 115-122. 
65. Magalhaes, F.C.; Ventura, C.E.H.; Abrao, A.M.; Denkena, B.; Breidenstein, B.; Meyer, K. Prediction of surface residual stress and hardness induced by ball burnishing through neural networks. Int. J. Manuf. Res. 2019, 14, 295-310. [CrossRef]

66. Stalin John, M.R.; Vinayagam, B.K. Optimization of nonlinear characteristics of ball burnishing process using Sugeno fuzzy neural system. J. Braz. Soc. Mech. Sci. Eng. 2014, 36, 101-109. [CrossRef]

67. Singh, J.; Bilga, P.S. Optimization of Dry Ball Burnishing Process Using Neuro-Fuzzy Interface System and Genetic Algorithm. In Proceedings of the International Conference on Research and Innovations in Mechanical Engineering, Guru Nanak Dev Engineering College, Ludhiana, Punjab, India, 24-26 October 2013; pp. 165-178. [CrossRef]

68. Meireles, M.R.G.; Almeida, P.E.M.; Simoes, M.G. A Comprehensive Review for Industrial Applicability of Artificial Neural Networks. IEEE Trans. Ind. Electron. 2003, 50, 585-601. [CrossRef]

69. Huang, T.M.; Kecman, V.; Kopriva, I. Kernel Based Algorithms for Mining Huge Data Sets; Springer: Berlin/Heidelberg, Germany, 2006.

70. Yu, H.; Kim, S. SVM Tutorial: Classification, Regression, and Ranking. In Handbook of Natural Computing; Rozenberg, G., Back, T., Kook, J.N., Eds.; Springer: Berlin/Heidelberg, Germany, 2012; pp. 479-506.

71. de Boor, C. A Practical Guide to Splines; Springer: New York, NY, USA, 1978.

72. Shin, S.; Jin, C.; Yu, J.; Rhee, S. Real-Time Detection of Weld Defects for Automated Welding Process Base on Deep Neural Network. Metals 2020, 10, 389. [CrossRef]

73. Casalino, G.; Losacco, A.M.; Arnesano, A.; Facchini, F.; Pierangeli, M.; Bonserio, C. Statistical analysis and modelling of an Yb: KGW femtosecond laser micro-drilling process. Procedia CIRP 2017, 62, 275-280. [CrossRef] 